\title{
Canopy and climate controls of gross primary production of Mediterranean-type deciduous and evergreen oak savannas
}

Jie Wang ${ }^{1}$, Xiangming Xiao ${ }^{1,2,{ }^{*}}$, Pradeep Wagle ${ }^{1}$, Siyan $\mathrm{Ma}^{3}$, Dennis Baldocchi ${ }^{3}$, Arnaud Carrara $^{4}$, Yao Zhang ${ }^{1}$, Jinwei Dong ${ }^{1}$, Yuanwei Qin ${ }^{1}$

${ }^{1}$ Department of Microbiology and Plant Biology, Center for Spatial Analysis, University of Oklahoma, Norman, OK 73019, USA

${ }^{2}$ Institute of Biodiversity Science, Fudan University, Shanghai, 200433, China

${ }^{3}$ Department of Environmental Science, Policy and Management, University of California, Berkeley, CA 94720, USA

${ }^{4}$ Fundación Centro de Estudios Ambientales del Mediterráneo (CEAM), Charles Robert Darwin, 14, Parque Tecnológico, 46980 Paterna, Spain

*Corresponding author: Xiangming Xiao, Ph.D.

Department of Microbiology and Plant Biology, University of Oklahoma

101 David L. Boren Blvd., Norman, Oklahoma 73019-5300, USA

Phone: (405) 325-8941

Email: xiangming.xiao@ou.edu (X. Xiao);

Website: http://www.eomf.ou.edu 
Abstract: Understanding the interactions of climate, vegetation growth, and gross primary production (GPP) is critical for accurate estimation of GPP over years. The eco-physiological response of two functional savannas (deciduous and evergreen) to temporal variations in biophysical factors under similar Mediterranean climate is still unclear. In this study, we compared dynamics of major climatic variables, eddy covariance (EC) tower-based GPP $\left(\mathrm{GPP}_{\mathrm{EC}}\right)$, and vegetation indices (VIs: normalized difference vegetation index (NDVI), enhanced vegetation index (EVI), and land surface water index (LSWI)) over the last decade in a deciduous savanna (Tonzi Ranch in California, USA) and an evergreen savanna (Las Majadas del Tietar in Caceres, Spain) under the Mediterranean climate. We also examined the relationships among VIs, GPP $\mathrm{EC}_{\mathrm{EC}}$ and major climatic variables in dry, normal, and wet hydrological years. Seasonal dynamics of climate variables and $\mathrm{GPP}_{\mathrm{EC}}$ were similar, but seasonal dynamics of VIs differed at two savanna sites. Both savannas' VIs and $\mathrm{GPP}_{\mathrm{EC}}$ had similar responses to air temperature. The evergreen savanna showed larger variations in VIs and GPP $\mathrm{EC}_{\mathrm{EC}}$ with respect to changes in annual precipitation than did the deciduous savanna. We simulated GPP of these two savanna sites using a light-use efficiency based Vegetation Photosynthesis Model (VPM). The modeled GPP ( $\left.\mathrm{GPP}_{\mathrm{vpm}}\right)$ at both savanna sites agreed well with the seasonal and interannual dynamics of $\mathrm{GPP}_{\mathrm{EC}}$ over the study period (slopes of $0.83-1.15$ and $\mathrm{R}^{2}$ values of 0.91-0.97). The LSWI-based water scalar parameter in VPM helped to accurately estimate GPP under dry, normal, and wet years. The results of this study help better understanding the ecophysiological response of evergreen and deciduous savannas, and also suggest the potential of VPM to simulate interannual variations of GPP in different types of Mediterranean-climate savannas through the integration of vegetation indices and climate data. 
Keywords: Vegetation Photosynthesis Model (VPM); Vegetation Index (VI); climate change; drought; NDVI

\section{Introduction}

Mediterranean-climate savannas provide many ecological services with rich species and unique natural and human landscapes (Baldocchi et al., 2010; Correia et al., 2014). These savannas are composed of sparse trees and continuous understory herbaceous cover, shaped by both human activities and ecological factors (Bugalho et al., 2011; Kobayashi et al., 2013; Marañón et al., 2009). These savannas experience large interannual variations in temperature, rainfall, and soil moisture (Joffre et al., 1999; Ma et al., 2007). In addition, climate models have projected large changes in the Mediterranean climate in this century, including increased mean air temperature, significantly reduced precipitation, more concentrated rainfall events, and longer drought periods (Gao and Giorgi, 2008; Hertig and Jacobeit, 2008). These factors are likely to result in even more complicated interannual variations in gross primary production (GPP) of Mediterranean-climate savanna ecosystems than that of sub-tropical, temperate, and boreal ecosystems (Ma et al., 2007). An accurate estimation of GPP for Mediterranean-climate savannas is, therefore, critical to better understand the feedbacks of these savannas to climate change.

In past decades, production efficiency models (PEMs) based on the light use efficiency (LUE) concept (Monteith, 1972) have been widely used to estimate GPP of terrestrial ecosystems (Goetz et al., 1999; Running et al., 2004; Turner et al., 2006; Veroustraete et al., 2002; Xiao et al., 2004a; Yuan et al., 2007). These PEMs estimate GPP as the product of photosynthetically active radiation (PAR), the fraction of absorbed PAR (FPAR), and LUE (Monteith, 1972; Potter 
et al., 1993). The tree-grass mixed and open canopies of Mediterranean-climate savannas present a challenge to accurate estimation of leaf area index and FPAR (Hilker et al., 2008; Ruimy et al., 1999; Ryu et al., 2010; Widlowski, 2010), which may in turn present a challenge for LUE-based GPP models to capture large interannual GPP variations due to year to year changes in temperature, rainfall, and soil moisture.

The LUE-based Vegetation Photosynthesis Model (VPM), which estimates GPP at temporal scales ranging from daily to 8-day, has successfully simulated GPP across a variety of terrestrial ecosystems including tropical savannas (Jin et al., 2013), croplands (Kalfas et al., 2011; Wagle et al., 2015b), grasslands (Wagle et al., 2014), and forests (Xiao et al., 2005a; Xiao et al., 2005b). VPM uses temperature (Tscalar) and water (Wscalar) down-regulation scalars to characterize the effects of these factors on LUE. Satellite-based land surface water index (LSWI) that can track drought-impacted vegetation (Bajgain et al., 2015; Wagle et al., 2014; Wagle et al., 2015b) is used in VPM to compute Wscalar. For these reasons, several GPP model comparison studies have shown VPM's performance to be better than several other commonly used GPP models in capturing the impacts of drought on GPP in grasslands (Dong et al., 2015; Wu et al., 2010). In this study, we evaluate the performance of VPM in estimating seasonal dynamics and interannual variability of GPP in two oak savannas sites (one deciduous savanna in the United States and one evergreen savanna in Spain). These two sites have comparable Mediterranean climates and have in-situ climate and carbon flux data over a decade (Casals et al., 2009; Gilabert et al., 2015; Ma et al., 2007).

The goals of this study were to (1) examine the seasonal dynamics and interannual variations of climate and vegetation growth of the Mediterranean-climate savannas based on flux 
observations and remote sensing data for a decade; and (2) estimate the potential of the LUEbased VPM to simulate GPP of the Mediterranean-climate savannas under different hydrological conditions. Three specific objectives of this study were to (1) understand the seasonal dynamics of major climatic variables (temperature, precipitation, and radiation), vegetation indices (VIs), and carbon flux of two dominant functional (evergreen and deciduous) savannas under the Mediterranean climate; (2) examine the relationships among temperature, precipitation, VIs, and GPP dynamics; and (3) simulate seasonal dynamics and interannual variations of GPP over dry, normal, and wet hydrological years, using VPM.

\section{Material and methods}

\subsection{Study sites}

\subsubsection{Tonzi Ranch (US-Ton) site}

The Tonzi Ranch site is located in California, USA $\left(38.4316^{\circ} \mathrm{N}, 120.9660^{\circ} \mathrm{W}\right.$, Fig. 1a). Dominant species are deciduous blue oaks (Quercus douglasii) and understory $\mathrm{C}_{3}$ grasses, with tree canopy cover of about $40 \%$. This site has a Mediterranean climate with dry and hot summers

(little summer precipitation), and wet and mild winters. The mean annual air temperature is 16.5 ${ }^{\circ} \mathrm{C}$ and the mean annual precipitation is $562 \mathrm{~mm}$. The landscape features and relevant information of this site are shown in Fig. $1 \mathrm{~b}$ and Table 1. Detailed information on the site can be found in an earlier publication (Ma et al., 2007).

\subsubsection{Las Majadas del Tietar (ES-LMa) site}

The Las Majadas del Tietar site is located at Caceres, Spain (39.9415 $\mathrm{N}, 5.7734^{\circ} \mathrm{W}$ Fig. 1a). Dominant species are evergreen holm oak trees (Quercus ilex ssp ballota Lam.) and annual $\mathrm{C}_{3}$ grasses, with tree canopy cover of about $20 \%$. This site experiences a Mediterranean climate and has a mean annual air temperature of $16.7^{\circ} \mathrm{C}$ and mean annual precipitation of $528 \mathrm{~mm}$ with 
summer precipitation comprising less than $6 \%$. The landscape features and relevant information of this site are shown in Fig. 1c and Table 1. Detailed information on the site can be found in an earlier publication (Casals et al., 2009).

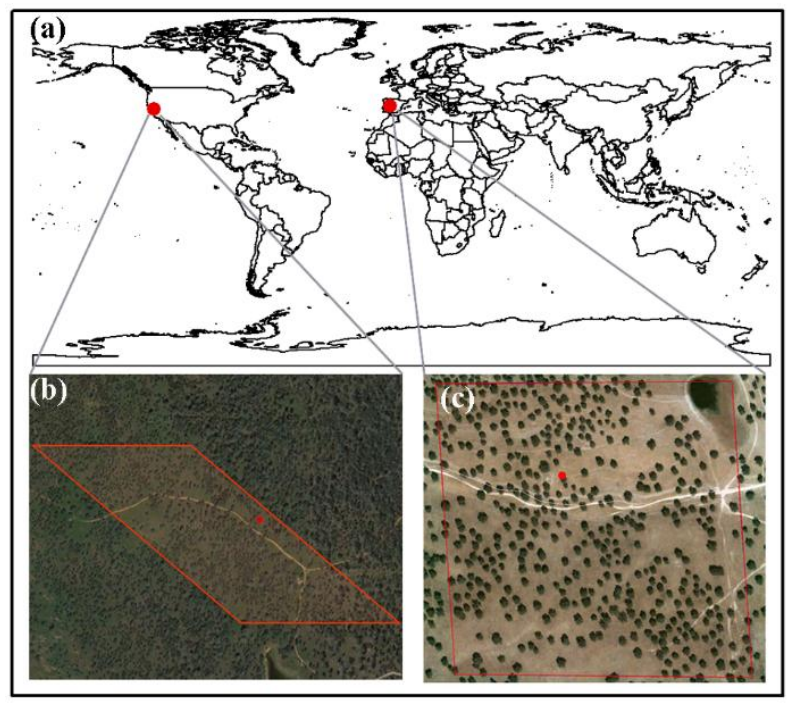

Fig. 1. Geolocation of two savanna flux tower sites in USA and Spain (a); landscapes at the USTon site, USA (b); and landscapes at the ES-LMa site, Spain (c). The red square line in Figures b and c corresponds to the size of one MODIS pixel at $500 \mathrm{~m}$ spatial resolution, and the red dot represents the location of the flux tower.

\begin{tabular}{|c|c|c|c|c|c|c|c|c|c|}
\hline $\begin{array}{l}\text { Site } \\
\text { code }\end{array}$ & $\begin{array}{l}\text { Site } \\
\text { name }\end{array}$ & Country & Lat & Lon & $\begin{array}{l}\text { Dominant } \\
\text { species }\end{array}$ & $\begin{array}{l}\text { MAP } \\
(\mathrm{mm})\end{array}$ & $\begin{array}{l}\text { MAT } \\
\left({ }^{\circ} \mathrm{C}\right)\end{array}$ & $\begin{array}{l}\text { Flux data } \\
\text { used }\end{array}$ & References \\
\hline US-Ton & Tonzi Ranch & US. & 38.4316 & -120.966 & $\begin{array}{l}\text { Deciduous blue } \\
\text { oak, C3 grass }\end{array}$ & 562 & 16.5 & $2002-2013$ & Ma et al. (2007) \\
\hline ES-LMa & $\begin{array}{l}\text { Las Majadas } \\
\text { del Tietar }\end{array}$ & Spain & 39.9403 & -5.7746 & $\begin{array}{l}\text { Evergreen holm } \\
\text { oak, C3 grass }\end{array}$ & 528 & 16.7 & 2004-2012 & $\begin{array}{l}\text { Casals et al. } \\
(2009)\end{array}$ \\
\hline
\end{tabular}

Table1. Summary of two savanna study sites,

\subsection{Data}

\subsection{1 $\mathrm{CO}_{2}$ flux and meteorological data}

The climate and carbon flux data used in this study were downloaded from the AmeriFlux website (http://ameriflux.ornl.gov/) for the US-Ton site and European Fluxes Database Cluster (http://www.europe-fluxdata.eu/) for the ES-LMa site. We acquired the gap-filled half-hourly 
level 2 data over twelve years (2002-2013) for the US-Ton site. For the ES-LMa site, we acquired level 4 weekly data over 8 years (2004-2011) and half-hourly level 2 data for 2012. We aggregated half hourly eddy covariance tower-based GPP (GPP $\left.{ }_{\mathrm{EC}}\right)$ and meteorological data into 8-day intervals to match the temporal resolution of MODIS-derived VIs.

\subsubsection{MODIS surface reflectance, vegetation indices, and GPP product}

This study used the MODIS 8-day land surface reflectance product (MOD09A1) at $500 \mathrm{~m}$ spatial resolution. It includes seven spectral bands: red $(620-670 \mathrm{~nm})$, blue $(459-479 \mathrm{~nm})$, green (545-565 nm), NIR1 (841-876 nm), NIR2 (1230-1250 nm), SWIR1 (1628-1652 nm), and SWIR2 (2105-2155 nm). Three vegetation indices: NDVI (Tucker, 1979), EVI (Huete et al., 2002; Huete et al., 1997), and land surface water index (LSWI) ) (Xiao et al., 2004a; Xiao et al., 2005b) were calculated using the blue, red, NIR1, and SWIR1 spectral bands as shown in equations 1-3. The MOD09A1 data were downloaded from the Earth Observation and Modeling Facility (EOMF) data portal at the University of Oklahoma (http://eomf.ou.edu/visualization/).

$$
\begin{aligned}
& N D V I=\frac{\rho_{N I R}-\rho_{\text {Red }}}{\rho_{\text {NIR }}+\rho_{\text {Red }}} \\
& E V I=2.5 \times \frac{\rho_{\text {NIR }}-\rho_{\text {Red }}}{\rho_{\text {NIR }}+6 \times \rho_{\text {Red }}-7.5 \times \rho_{\text {Blue }}+1} \\
& L S W I=\frac{\rho_{N I R}-\rho_{\text {SWIR }}}{\rho_{\text {NIR }}+\rho_{\text {SWIR }}}
\end{aligned}
$$

The MODIS land science team provides the global standard MODIS GPP (GPP $\left.{ }_{\text {mod }}\right)$ product (MOD17A2) at $1 \mathrm{~km}$ spatial resolution and 8-day temporal resolution (Running et al., 2004; 
Zhao and Running, 2010; Zhao et al., 2005). MOD17A2 data (version-55 of 2002-2012, version5 of 2013) were downloaded from NASA LAADS website (https://ladsweb.nascom.nasa.gov/data/search.html) for the model comparison.

\subsection{Analysis of climate, vegetation indices, and carbon flux data}

We examined the seasonal and interannual dynamics of PAR, mean air temperature $\left(\mathrm{T}_{\text {air }}\right)$,

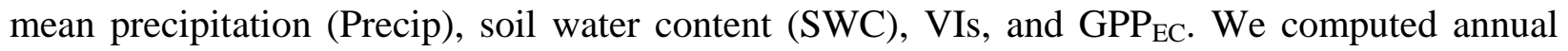
precipitation $\left(\mathrm{AP}_{\text {hyd }}\right)$, mean annual precipitation $\left(\mathrm{MAP}_{\text {hyd }}\right)$, and standard deviation of annual precipitation $\left(\mathrm{SD}_{\text {hyd }}\right)$ over each hydrological (hyd) year (hydrological year begins in September and ends in August of the following year) across the study period. There is not a universal physical variable to quantitatively describe the types of the hydrological years (dry, normal, and wet years) at the annual scale. Precipitation is a main variable determining the humidity and dryness (Chang and Kleopa, 1991; Heim, 2002). In addition, drought indices are usually used to monitor different types of hydrological systems (McKee et al., 1993; Palmer, 1965; VicenteSerrano et al., 2010). The Standardized Precipitation Evapotranspiration Index (SPEI) is the difference between precipitation (P) and Potential Evapotranspiration (PET) (Vicente-Serrano et al., 2010). This climatic water balance-based drought index includes the effects of precipitation and temperature variations on drought assessment. A global assessment showed good performance of the SPEI to capture drought impacts on agriculture, ecology, and hydrology (Vicente-Serrano et al., 2012). More information about the SPEI was shown in SI Appendix. To explore the responses of these two savannas to the interannual variations of precipitation, and to evaluate the performance of VPM under different hydrological conditions, we classified the study period into three types of hydrological years (dry, normal, and wet) based on annual precipitation and the SPEI. 
We performed simple regression analysis between VIs (NDVI and EVI) and GPP EC $_{\text {over the }}$ growing season to understand how vegetation greenness is related to canopy photosynthesis in these two savanna ecosystems. The growing season was defined as the period when $\mathrm{GPP}_{\mathrm{EC}}>1 \mathrm{~g}$ $\mathrm{C} \mathrm{m}^{-2}$ day $^{-1}$ as in previous studies (Dong et al., 2015; Jin et al., 2013; Wagle et al., 2014).

The responses of EVI and GPP to daytime mean air temperature $\left(\mathrm{T}_{\text {air_daytime }}\right)$ were examined to determine the optimal temperature $\left(\mathrm{T}_{\mathrm{opt}}\right)$ parameter for GPP simulation in VPM. We categorized 8-day EVI and $\mathrm{GPP}_{\mathrm{EC}}$ from both sites into different temperature classes at $1^{\circ} \mathrm{C}$ interval and computed mean EVI and $\mathrm{GPP}_{\mathrm{EC}}$ in all years for each temperature bin. Similarly, we also computed mean EVI and GPP $\mathrm{EC}_{\mathrm{E}}$ only in wet years for each temperature bin to exclude the potential influence of water stress in dry years on determining $\mathrm{T}_{\text {opt }}$. The $\mathrm{T}_{\text {air_daytime }}$ at the maximum turning point (the inflection point) of the EVI and $\mathrm{GPP}_{\mathrm{EC}}$ curves was selected as $\mathrm{T}_{\mathrm{opt}}$.

\subsection{GPP simulation from VPM}

The satellite-based VPM was developed to estimate vegetation GPP over the photosynthetically active period (Xiao et al., 2004a; Xiao et al., 2004b). The VPM estimates GPP as the product of $L U E, F P A R_{c h l}$, and PAR.

$G P P_{V P M}=\varepsilon_{g} \times F P A R_{c h l} \times P A R$

where $\varepsilon_{\mathrm{g}}$ is the LUE $\left(\mathrm{g} \mathrm{C} \mathrm{mol}^{-1}\right.$ photosynthetic photon flux density, PPFD), FPAR $\mathrm{C}_{\mathrm{chl}}$ is the fraction of PAR absorbed by chlorophyll, and PAR is the photosynthetically active radiation.

$F P A R_{c h l}$ is estimated as a linear function of EVI (Eq. 5), and the coefficient a is set to be 1.0 following previous studies (Xiao et al., 2005a; Xiao et al., 2004b). 
$\varepsilon_{g}$ is estimated as the down-regulation of maximum light use efficiency $\varepsilon_{0}\left(\mathrm{~g} \mathrm{C} \mathrm{mol}^{-1} \mathrm{PPFD}\right)$ with temperature and water scalars to account for temperature and water stresses as shown in Eq. (6).

$\varepsilon_{g}=\varepsilon_{0} \times T_{\text {scalar }} \times W_{\text {scalar }}$

$\varepsilon_{0}$ varies based on vegetation functional types $\left(\mathrm{C}_{3}\right.$ or $\mathrm{C}_{4}$ biomes) in the VPM. The estimation methods include literature surveys and site-based analysis of NEE and photosynthetic photon flux density (PPFD) (Xiao, 2006). In this study, $\varepsilon_{0}$ was determined from the NEE-PPFD relationship as shown in previous studies (Wagle et al., 2014, Wagle et al., 2015). The Michaelis-Menten function (Eq. 7) was used to estimate $\varepsilon_{0}$ at an ecosystem level based on two weeks of half-hourly flux data during peak savanna growth (May 13-26, 2010 for the US-Ton site, May 3-16, 2010 for the ES-LMa site). These periods were selected based on the maximum 8-day NEE or GPP values for the study sites. Based on this analysis, we used the $\varepsilon_{0}$ value of $0.042 \mathrm{~mol} \mathrm{CO}_{2} \mathrm{~mol}^{-1}$ PPFD or $0.5 \mathrm{~g} \mathrm{C} \mathrm{mol}^{-1}$ PPFD (Fig. 2) for both sites across all site-years.

$N E E=\frac{\varepsilon_{0} \times G P P_{\max } \times P P F D}{\varepsilon_{0} \times P P F D+G P P_{\max }}+E R$

where $\mathrm{GPP}_{\max }$ is the maximum canopy $\mathrm{CO}_{2}$ uptake rate $\left(\mu \mathrm{molm}^{-2} \mathrm{~s}^{-1}\right)$ at light saturation and ER is ecosystem respiration. 
$T_{\text {scalar }}$ was estimated at each time step based on the relationship between stomatal conductance and air temperature (Jarvis, 1976) following the equation used in the Terrestrial Ecosystem Model (Raich et al., 1991).

$T_{\text {scalar }}=\frac{\left(T-T_{\min }\right)\left(T-T_{\max }\right)}{\left(T-T_{\min }\right)\left(T-T_{\max }\right)-\left(T-T_{o p t}\right)^{2}}$

where $T_{\min }, T_{\max }$, and $T_{\text {opt }}$ are minimum, maximum, and optimal temperatures for photosynthetic activities, respectively. We set $T_{\min }$ and $T_{\max }$ values to be $0^{\circ} \mathrm{C}$ and $50^{\circ} \mathrm{C}$ considering the lethal effects of cold temperature (frost) and extreme heat on plant growth and development. $\mathrm{T}_{\min }$ and $\mathrm{T}_{\max }$ are generally selected in such a way that the sites do not experience that level of too low or high temperature during the growing season. $T_{\text {opt }}$ for photosynthesis varies widely among different vegetation types (Baldocchi et al., 2001; Medlyn et al., 2002; Sims et al., 2008). Two sites had different portions of grass and tree covers which might alter $T_{\text {opt }}$. In this study, the sitespecific $T_{\text {opt }}$ was, therefore, estimated using the method described in section 2.3. As photosynthesis occurs in daytime, we used daytime mean air temperature instead of the daily mean air temperature to calculate the $T_{\text {scalar }}$.

$W_{\text {scalar }}$ was estimated based on the satellite-derived land surface water index (LSWI) as:

$W_{\text {scalar }}=\frac{1+L S W I}{1+L S W I_{\max }}$

Where $L S W I_{\max }$ is the maximum LSWI within the growing season for individual pixels. 


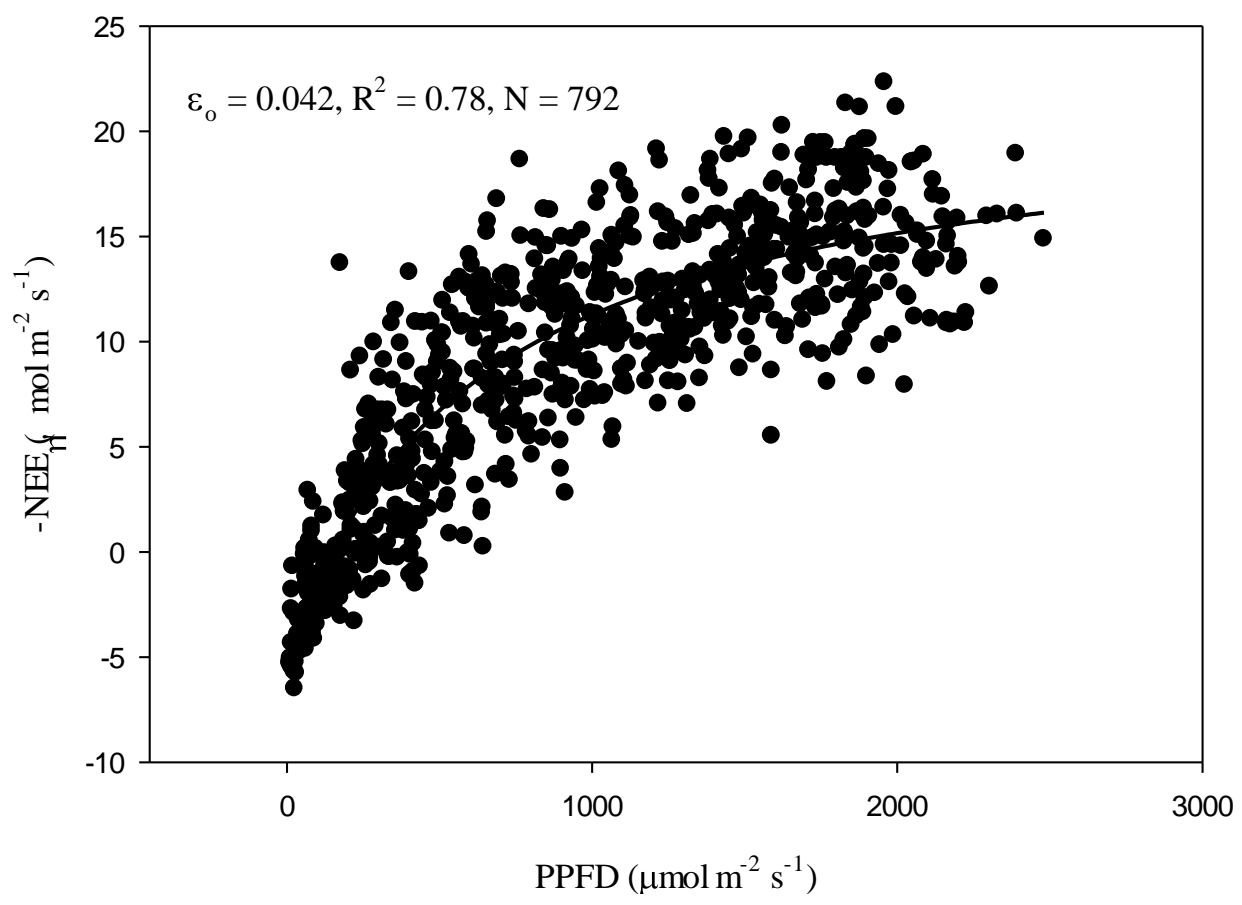

Fig. 2 Light-response curve function based on two weeks of flux tower measurements during the selected time periods (May 13-26, 2010 for the US-Ton site, May 3-16, 2010 for the ES-LMa site). Data points represent 30-minute daytime net ecosystem $\mathrm{CO}_{2}$ exchange (NEE) values and data were pooled for both sites. PPFD is photosynthetic photon flux density. $\varepsilon_{0}$ is the apparent quantum yield (mol CO${ }^{2} \mathrm{~mol}^{-1}$ of photon) from the initial slope of the light-response curve.

\section{Results}

\subsection{Seasonal dynamics and interannual variations of climate, vegetation indices, and GPP EC}

The seasonal dynamics and interannual variations of PAR, $\mathrm{T}_{\text {air }}, \mathrm{SWC}$, and Precip at two savanna sites are shown in Fig. 3 and Table 2. Both sites had similar seasonal dynamics of PAR and $\mathrm{T}_{\text {air }}$, with PAR ranging from 10 to $70 \mathrm{~mol} \mathrm{~m}^{-2} \mathrm{day}^{-1}$ and $\mathrm{T}_{\text {air }}$ ranging from 4 to $35^{\circ} \mathrm{C}$. $\mathrm{SWC}$ at the US-Ton site ranged from $10 \%$ to $40 \%$ and dropped significantly below $15 \%$ in dry seasons, while SWC at the ES-LMa site ranged from $2 \%$ to $40 \%$ and was approximately 5\% in dry seasons. In general, rainfall mainly occurred in autumn, winter, and the next spring at both sites (Fig. 3d). Over the study period, the US-Ton site had a $\mathrm{MAP}_{\text {hyd }}$ of $549 \mathrm{~mm}$ (Fig. S1a, Table 2) with summer precipitation less than $1 \%$. And the ES-LMa site had a MAP hyd $_{\text {of }} 633 \mathrm{~mm}$ (Fig. 
S1b, Table 2) with summer precipitation about 5\%. The monthly SPEI time series for both sites are shown in Fig. S1. We identified the wet, normal and dry years based on the intensity and duration of the monthly SPEI and the annual precipitation. We identified four dry years (20062007, 2007-2008, 2008-2009, and 2012-2013), three normal years (2002-2003, 2003-2004, 2009-2010), and four wet years (2004-2005, 2005-2006, 2010-2011, and 2011-2012) at the USTon site. Similarly, at the ES-LMa site, we identified four dry years (2004-2005, 2007-2008, 2008-2009, and 2011-2012), one normal year (2005-2006), and three wet years (2006-2007, 2009-2010, and 2010-2011). 


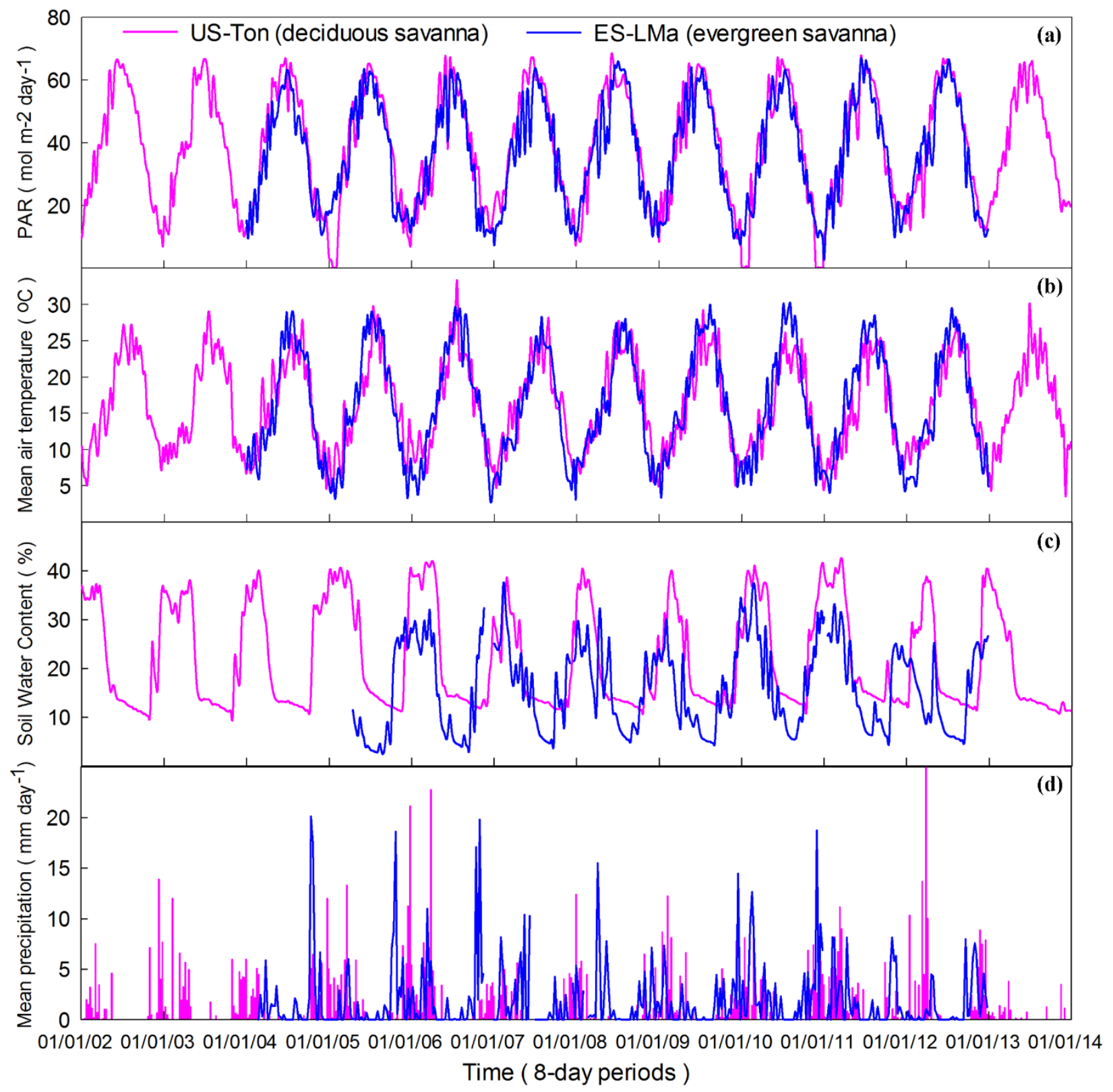

Fig. 3. Seasonal dynamics and interannual variations (8-day values) of photosynthetically active radiation (PAR), daily mean air temperature, soil water content, and precipitation at two savanna sites over the study period.

\begin{tabular}{cccccc}
\hline Site & Year & Ta & $\begin{array}{c}\text { PAR } \\
\left(\mathrm{mol} \mathrm{m}^{-2} \text { day }^{-1}\right)\end{array}$ & $\begin{array}{c}\text { Precipitation } \\
(\mathrm{mm})\end{array}$ & SWC (\%) \\
\hline US-Ton & $2002-2003$ & 17.3 & 42.3 & 391 & 22.3 \\
& $2003-2004$ & 15.8 & 39.3 & 367 & 22.4 \\
& $2004-2005$ & 15.0 & 35.7 & 723 & 28.9 \\
& $2005-2006$ & 16.5 & 36.9 & 952 & 24.1 \\
& $2006-2007$ & 16.0 & 40.2 & 381 & 20.9
\end{tabular}




$\begin{array}{cccccc} & 2008-2009 & 15.6 & 39.3 & 508 & 21.6 \\ 2009-2010 & 17.6 & 48.8 & 314 & 24.2 \\ 2010-2011 & 15.2 & 40.6 & 886 & 25.8 \\ 2011-2012 & 16.5 & 40.4 & 746 & 19.8 \\ 2012-2013 & 16.8 & 40.2 & 393 & 21.1 \\ \text { ES-LMa } & \text { Average } & 16.2 & 40.3 & 549 & 22.8 \\ & \text { SD } & 0.7 & 3.0 & 212 & 2.5 \\ & 2004-2005 & 16.2 & 37.2 & 562 & 18.3 \\ & 2005-2006 & 15.4 & 34.8 & 685 & 18.6 \\ & 2006-2007 & 15.2 & 33.5 & 876 & 16.4 \\ & 2007-2008 & 15.6 & 38.7 & 528 & 14.7 \\ 2008-2009 & 15.9 & 37.6 & 403 & 19.2 \\ & 2009-2010 & 16.1 & 35.0 & 763 & 19.4 \\ 2010-2011 & 15.7 & 35.4 & 839 & 17.6 \\ 2011-2012 & 13.0 & 35.0 & 339 & 1.5\end{array}$

Table 2. Summary of mean air temperature (Ta), mean photosynthetically active radiation (PAR), accumulated precipitation, and mean soil water content (SWC) at two ssavanna sites. Dry years are highlighted by red, normal years are highlighted by green and wet years are highlighted by blue.

Seasonal dynamics of VIs (NDVI, EVI, and LSWI) and GPP EC $_{\text {at }}$ both savanna sites varied from year to year depending on environmental drivers (Fig. 4). As both sites did not experience severe water stress in 2005-2006, 2009-2010 and 2010-2011, we compared the VIs and GPP dynamics at two savanna sites during those three hydrological years. At both sites, $\mathrm{GPP}_{\mathrm{EC}}$ showed similar seasonal dynamics: started to increase and exceeded $1 \mathrm{~g} \mathrm{C} \mathrm{m}^{-2} \mathrm{day}^{-1}$ during autumn, peaked in the following spring, then decreased to $1 \mathrm{~g} \mathrm{C} \mathrm{m}^{-2}$ day $^{-1}$ or less in summer. This suggests that vegetation in these two savannas greened up during autumn and entered into senescence in summer. These GPP seasonal patterns showed close correspondence with the seasonal patterns of VIs, as VIs started to increase in autumn, declined rapidly before summer, and remained low throughout the summer. However, VIs at the ES-LMa site peaked in winter and exhibited a high plateau during the growing season from winter to next spring, while VIs at 
the US-Ton site peaked in spring and did not exhibit a high plateau during the entire growing season. Although VIs peaked in different periods at two sites, peak $\mathrm{GPP}_{\mathrm{EC}}$ occurred at almost the same time (Fig. 4).
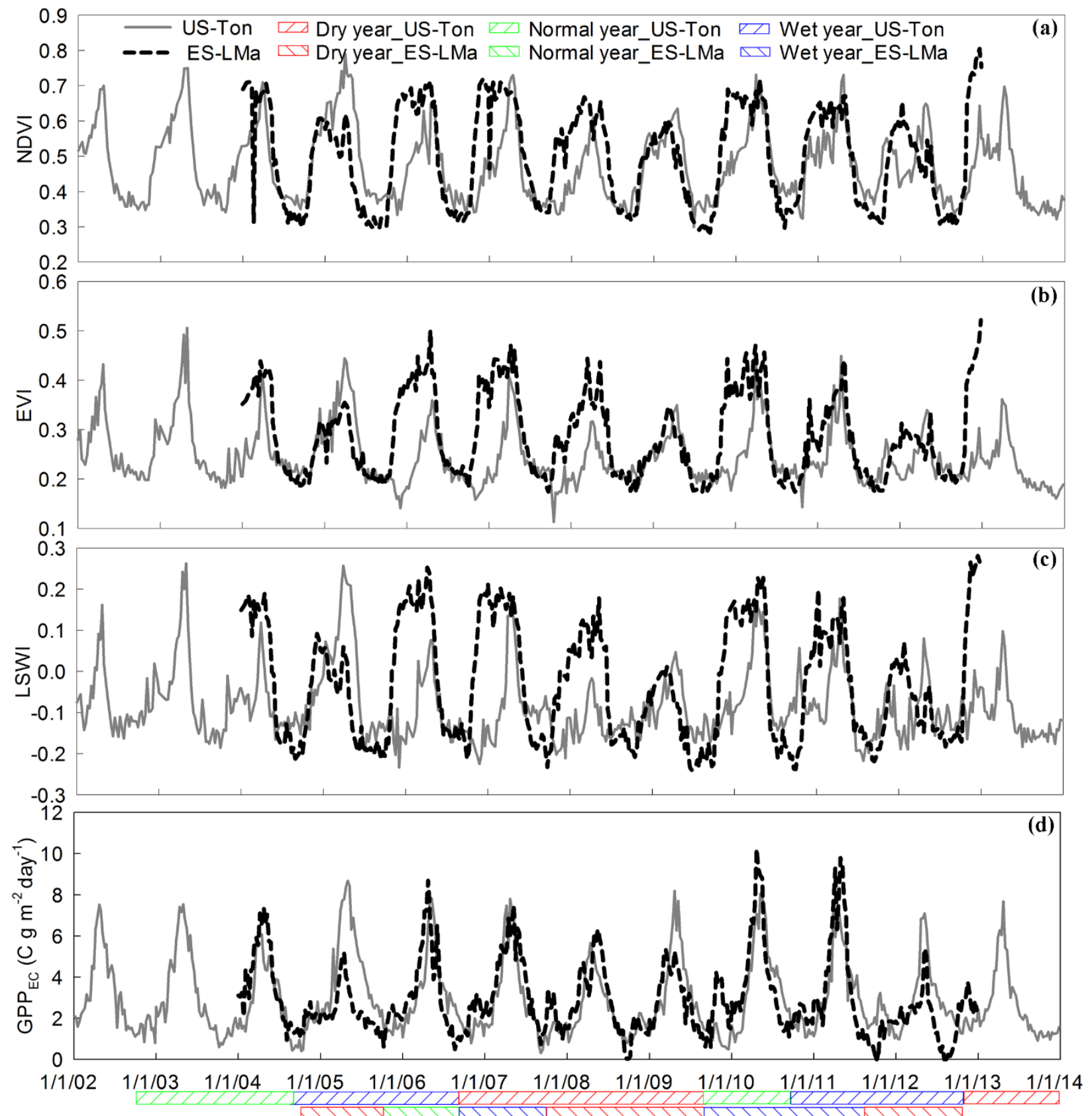

Time ( 8-day periods )

Fig. 4. Seasonal and interannual variations in MODIS-derived vegetation indices (normalized difference vegetation index, NDVI, enhanced vegetation index, EVI, and land surface water index, $\mathrm{LSWI})$ and tower-derived gross primary production $\left(\mathrm{GPP}_{\mathrm{EC}}\right)$ at two savanna sites. 


\subsection{The relationships among climate, vegetation indices, and $\mathrm{GPP}_{\mathrm{EC}}$}

Relationships between VIs (NDVI and EVI) and $\mathrm{GPP}_{\mathrm{EC}}$ during the plant growing season were examined under four scenarios: over the entire study period; dry years; normal years; and wet years (Fig. 5). NDVI and EVI accounted for more variabilities of $\mathrm{GPP}_{\mathrm{EC}}$ at the US-Ton site $\left(R^{2}=0.36\right.$ and 0.55 , respectively, Fig. $\left.5(a, b)\right)$ than at the ES-LMa site $\left(R^{2}=0.20\right.$ and 0.33 , respectively, Fig. $5(\mathrm{e}, \mathrm{f}))$ over the entire study period. Comparison of the relationships between $\mathrm{GPP}_{\mathrm{EC}}$ and VIs in dry, normal, and wet years showed that the relationships were stronger in dry years at both sites (Fig. $5(\mathrm{c}, \mathrm{d}, \mathrm{f})$ ). These results indicated that $\mathrm{GPP}_{\mathrm{EC}}$ was more sensitive to the variations in EVI at both savanna sites in dry years. In addition, EVI explained more variances of $\mathrm{GPP}_{\mathrm{EC}}$ than did NDVI in each scenario at both sites. 


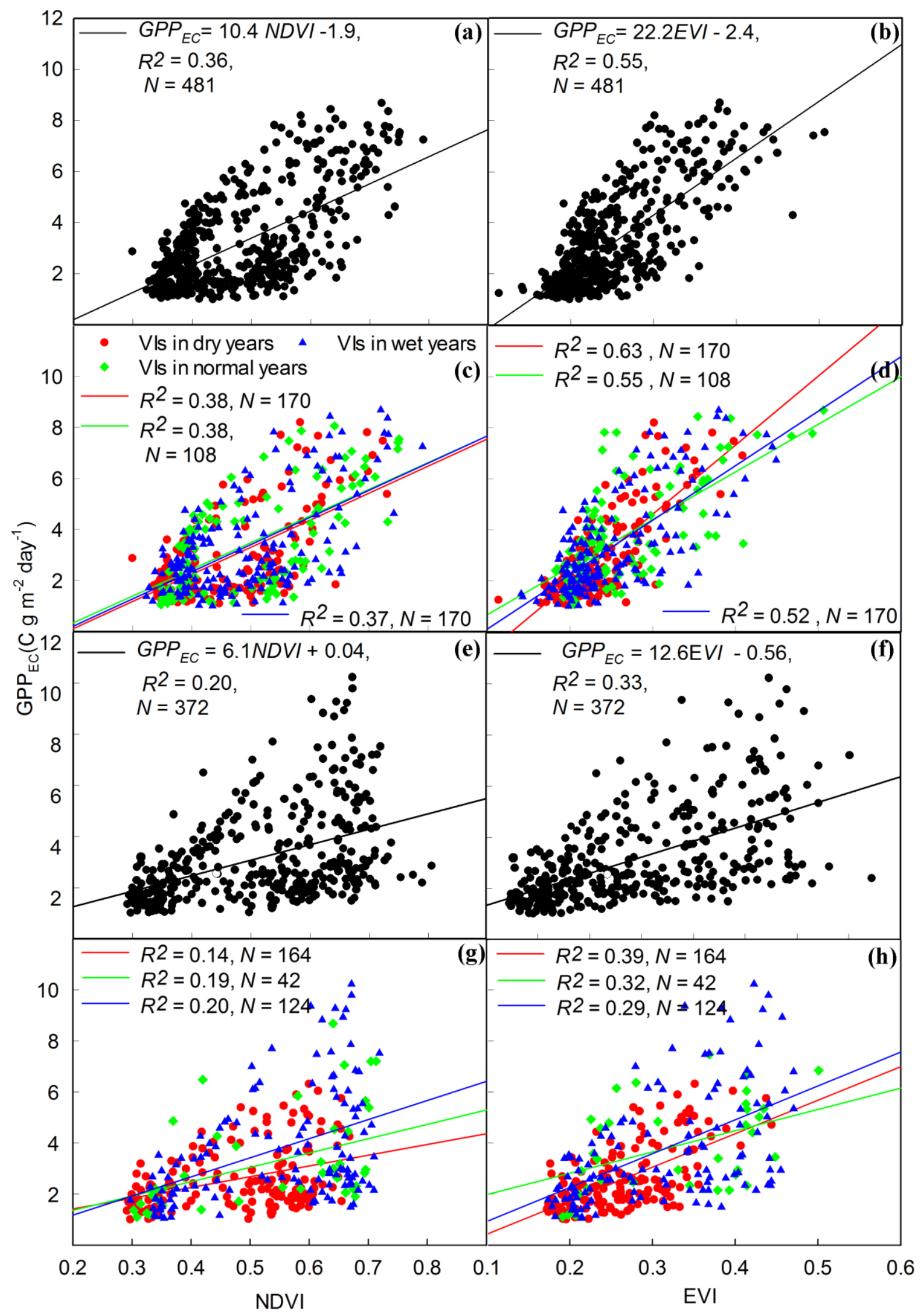


Fig. 5. Simple liner regression between tower-derived gross primary production $\left(\mathrm{GPP}_{\mathrm{EC}}\right)$ and vegetation indices (NDVI and EVI) during the growing season: US-Ton site (Fig. 5a,b,c,d) and ES-LMa site (Fig. 5e,f,g,h).

Fig. 6 shows the responses of EVI and GPP $\mathrm{EC}_{\text {to }} \mathrm{T}_{\text {air_daytime }}$ during the plant growing season. Both GPP $\mathrm{EC}_{\mathrm{EC}}$ and EVI increased rapidly with increasing $\mathrm{T}_{\text {air_daytime }}$ up to a certain threshold then decreased as $T_{\text {air_daytime }}$ increased. At the US-Ton site, when GPP $\mathrm{EC}_{\text {and }}$ EVI in all years were plotted against $\mathrm{T}_{\text {air_daytime, }}$, maximum $\mathrm{GPP}_{\mathrm{EC}}$ and $\mathrm{EVI}$ occurred at $18{ }^{\circ} \mathrm{C}$ and $15^{\circ} \mathrm{C}$, respectively

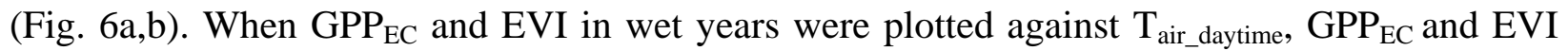
peaked at $18{ }^{\circ} \mathrm{C}$ (Fig. 6c,d). Similarly, at the ES-LMa site, the peak values of GPP ${ }_{\mathrm{EC}}$ and EVI occurred at $16{ }^{\circ} \mathrm{C}$ and $12{ }^{\circ} \mathrm{C}$, respectively, when data for all years were used (Fig. 6e,f) and they occurred at $14^{\circ} \mathrm{C}$ when data in wet years were used (Fig. 6g,h). Based on these results, we used $18^{\circ} \mathrm{C}$ and $14^{\circ} \mathrm{C}$ as the $\mathrm{T}_{\text {opt }}$ for the US-Ton site and the ES-LMa site, respectively, for the GPP simulation in VPM.

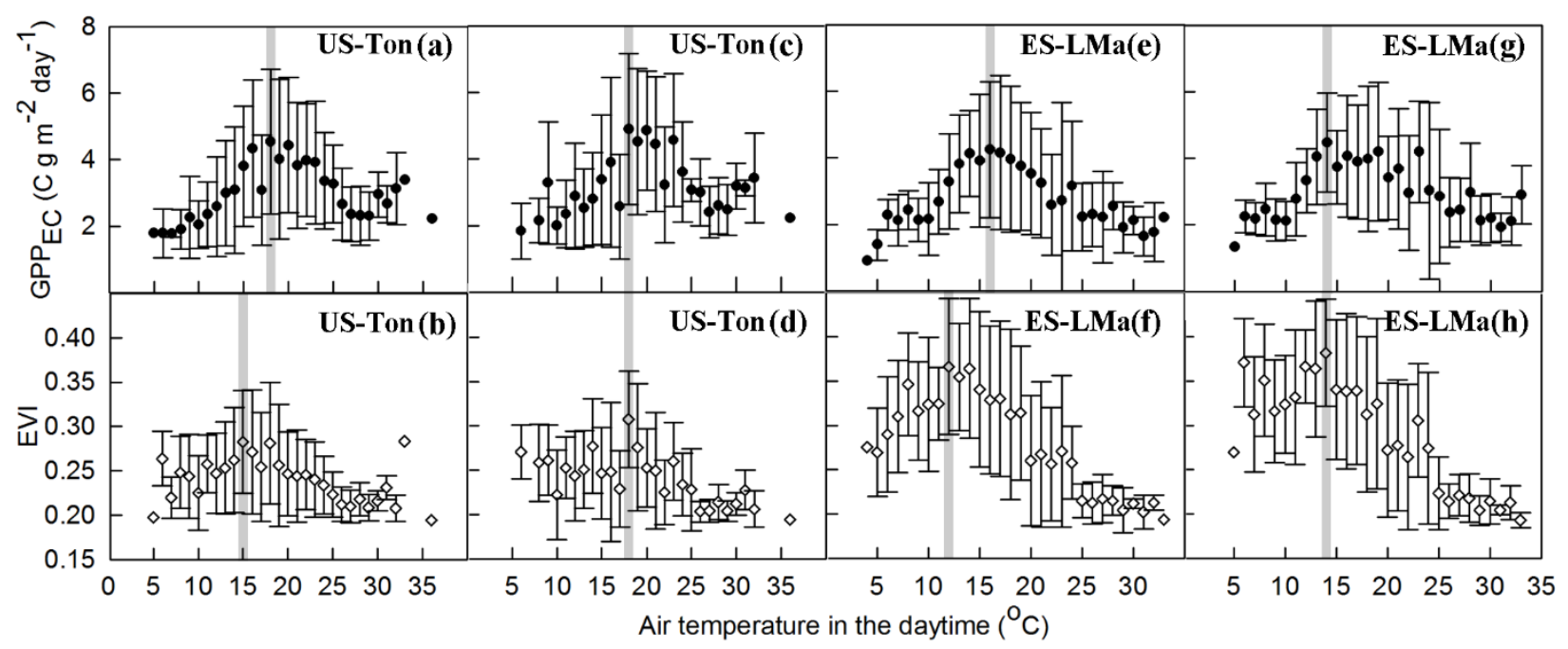

Fig. 6. Responses of tower-derived gross primary production $\left(\mathrm{GPP}_{\mathrm{EC}}\right)$ and enhanced vegetation index (EVI) to daytime air temperature at two savanna sites. Figures 6a,b,e,f were based on all hydrological years' data and Figures $6 \mathrm{c}, \mathrm{d}, \mathrm{g}, \mathrm{h})$ were based on wet years' data. Grey boxes show the maximum $\mathrm{GPP}_{\mathrm{EC}}$ or EVI. 
We compared the responses of VIs and $\mathrm{GPP}_{\mathrm{EC}}$ to the variations of hydrological conditions (dry, normal, and wet years) at the annual scale between these two savanna sites (Fig. 7). As shown, following a hydrological annual precipitation gradient from wet to dry years, VIs and $\mathrm{GPP}_{\mathrm{EC}}$ at the ES-LMa site decreased substantially, while VIs and GPP $\mathrm{EC}_{\mathrm{EC}}$ at the US-Ton site showed little change. LSWI had the largest sensitivity to the variations of annual hydrological conditions than did NDVI and EVI.

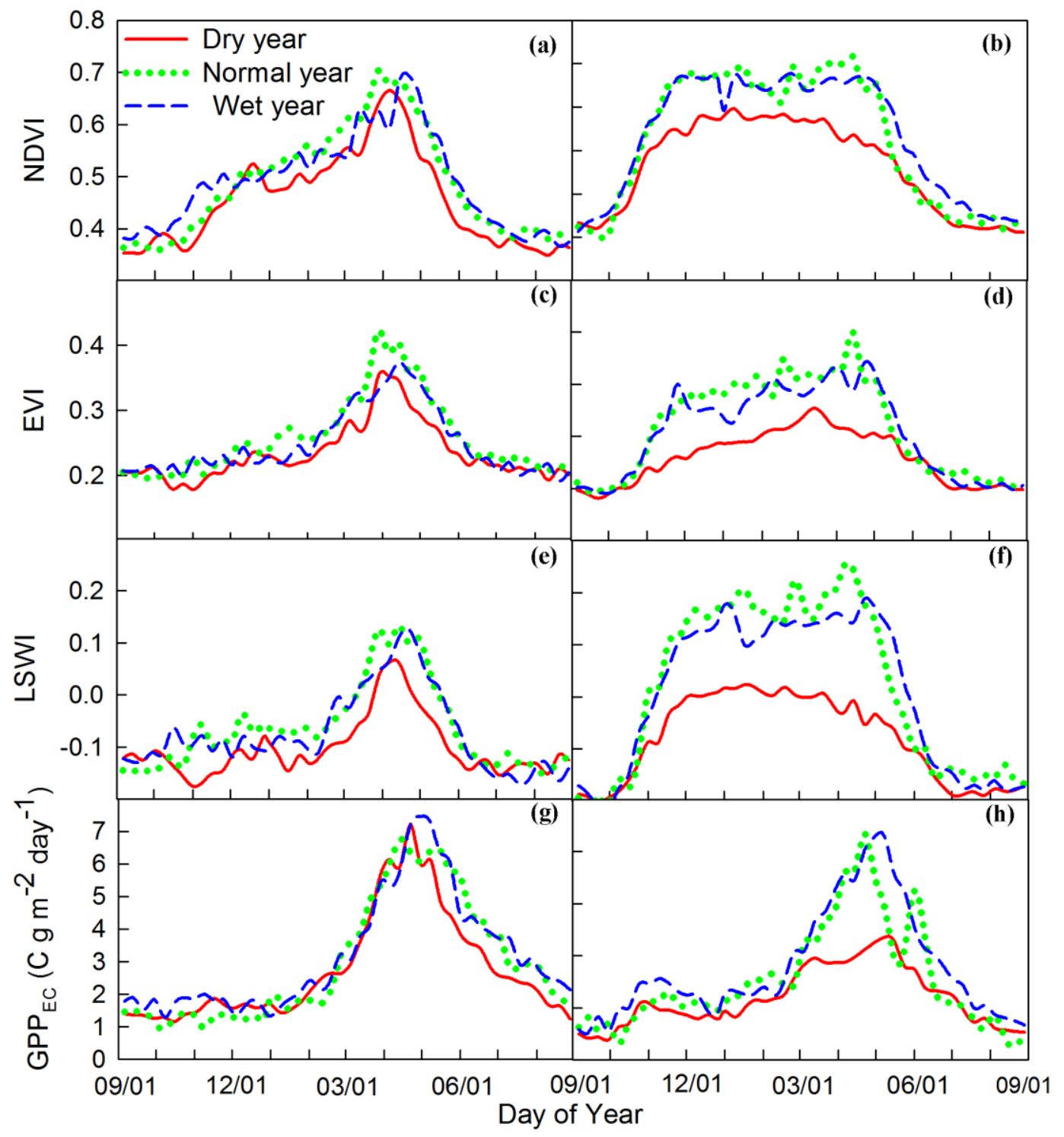

Fig. 7. Mean seasonal variation (8-day values) of three MODIS-derived vegetation indices (NDVI, EVI, and LSWI) and tower-derived gross primary production (GPP $\mathrm{EC}_{\mathrm{EC}}$ at two savanna 
sites (Fig. 7a,c,e,g for US-Ton site; Fig. 7b,d,f,h for ES-LMa site). Data were averaged by day of year over dry, normal, and wet years.

\subsection{GPP predicted by the VPM}

Fig. 8 shows that $\mathrm{GPP}_{\mathrm{vpm}}$ tracked the seasonal dynamics and interannual variations of $\mathrm{GPP}_{\mathrm{EC}}$ reasonably well over the study period at both sites. A simple linear regression analysis showed a good correlation between $\mathrm{GPP}_{\mathrm{vpm}}$ and $\mathrm{GPP}_{\mathrm{EC}}$ for the entire study period and different hydrological (dry, normal, and wet) years with slopes of 0.91-1.06 and $\mathrm{R}^{2}$ of 0.93-0.95 (Fig. 9). Linear regression coefficients for each year in Table 3 also showed that $\mathrm{GPP}_{\mathrm{vpm}}$ was strongly correlated with $\mathrm{GPP}_{\mathrm{EC}}$ at both sites with slopes $>0.83$ and $\mathrm{R}^{2}>0.90$. Comparison of the seasonally integrated $\mathrm{GPP}_{\mathrm{vpm}}$ and $\mathrm{GPP}_{\mathrm{EC}}$ at both sites showed that VPM slightly overestimated GPP in some normal and dry years (for example, in 2002-2003 at the US-Ton site and in 20112012 at the ES-LMa site) and slightly underestimated GPP in some wet years (for example, in 2004-2005 at the US-Ton site and in 2010-2011 at the ES-LMa site). At the US-Ton site, annual $\mathrm{GPP}_{\mathrm{EC}}$ ranged from 822 to $1319 \mathrm{~g} \mathrm{C} \mathrm{m}^{-2}$ and $\mathrm{GPP}_{\mathrm{vpm}}$ ranged from 885 to $1214 \mathrm{~g} \mathrm{C} \mathrm{m}^{-2}$ over the study period. At the ES-LMa site, annual $\mathrm{GPP}_{\mathrm{EC}}$ ranged from 603 to $1328 \mathrm{~g} \mathrm{C} \mathrm{m}^{-2}$ and $\mathrm{GPP}_{\mathrm{vpm}}$ ranged from 715 to $1222 \mathrm{~g} \mathrm{C} \mathrm{m}^{-2}$ over the study period. 


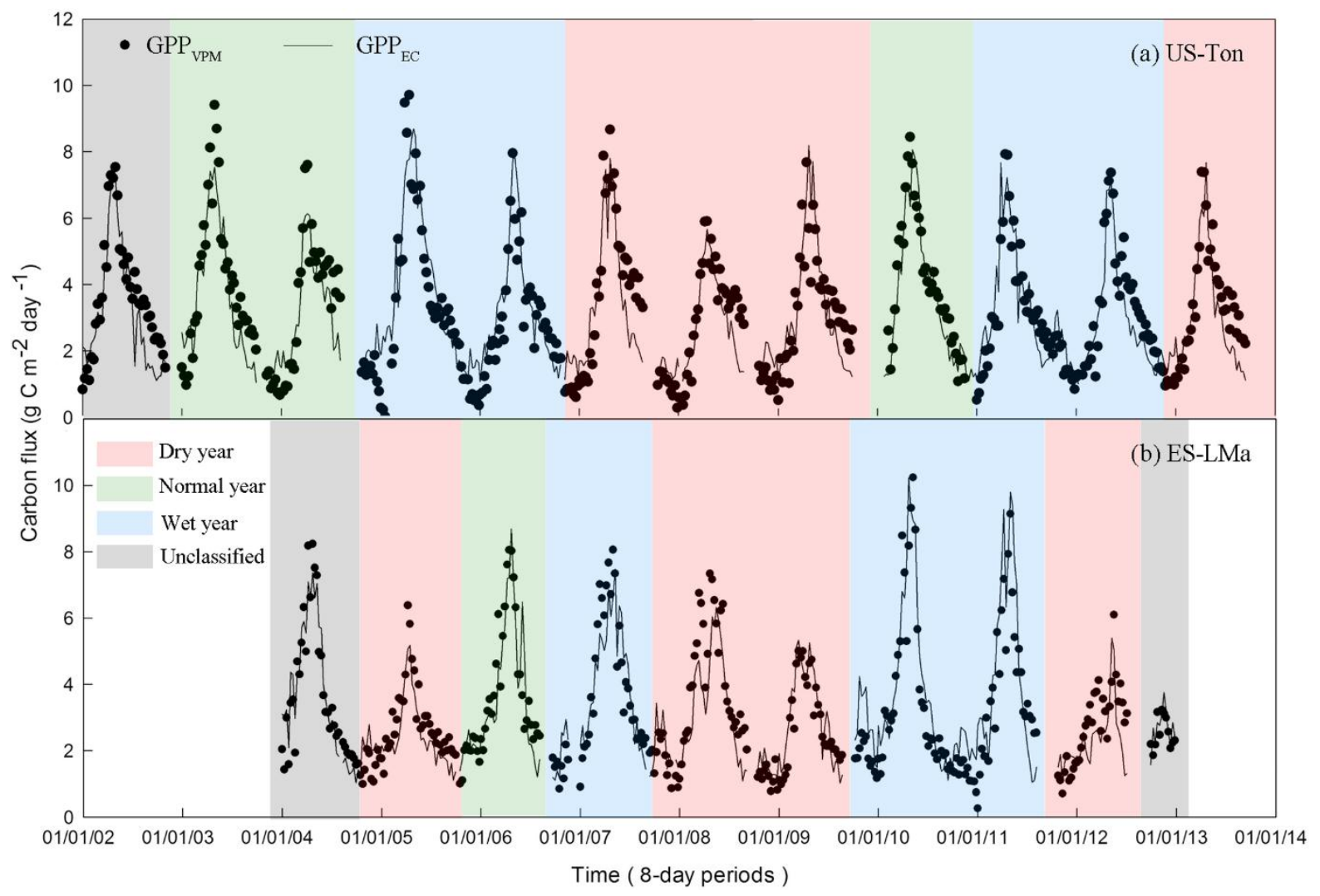

Fig. 8. A comparison between seasonal dynamics and interannual variations of tower-derived gross primary production $\left(\mathrm{GPP}_{\mathrm{EC}}\right)$ and simulated $\mathrm{GPP}\left(\mathrm{GPP}_{\mathrm{vpm}}\right)$ at two savanna sites. 


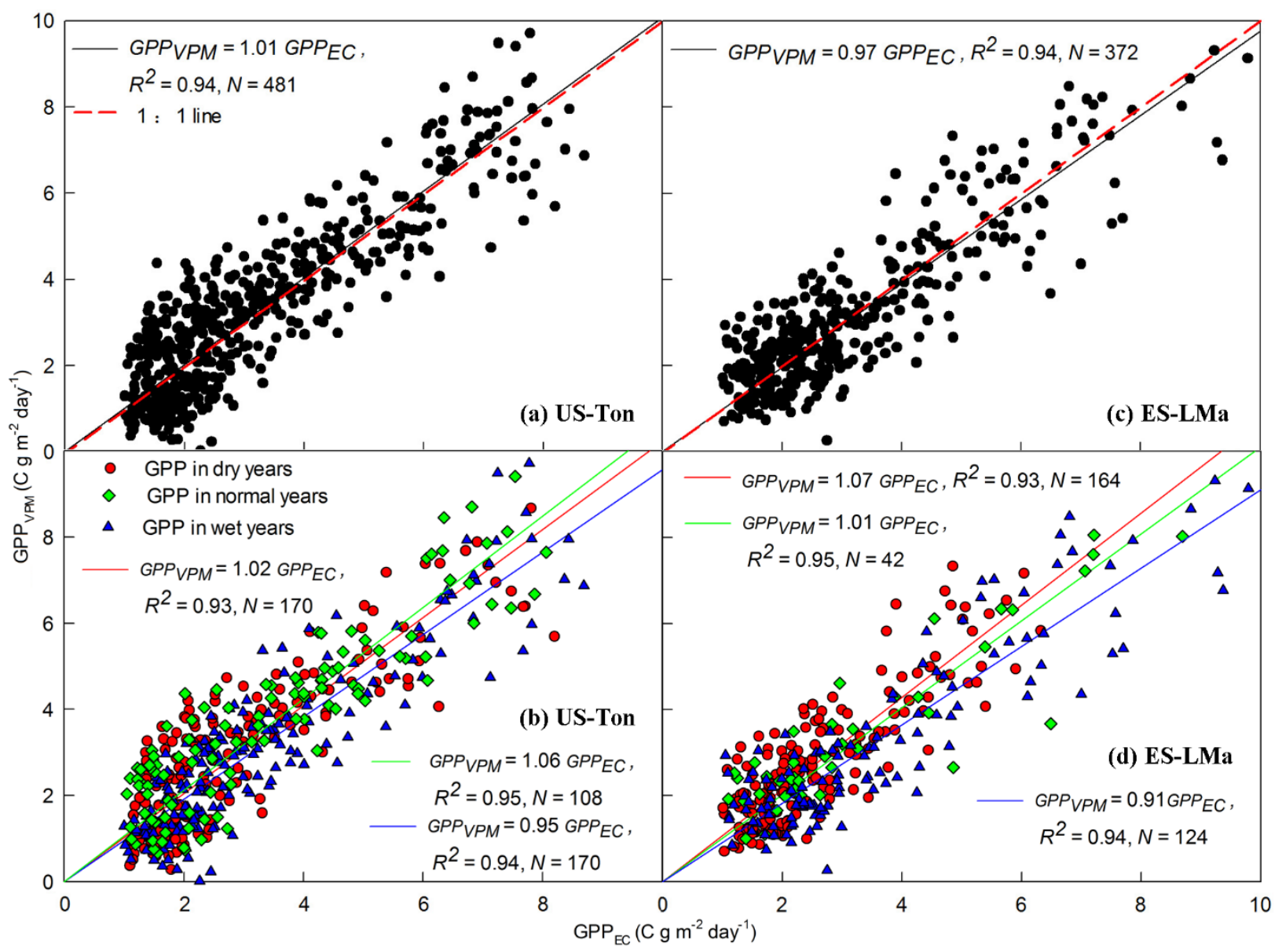

Fig. 9. Linear relationship between tower-derived gross primary production $\left(\mathrm{GPP}_{\mathrm{EC}}\right)$ and simulated GPP (GPP $\left.\mathrm{Gpm}_{\mathrm{v}}\right)$ at two savanna sites: aggregated over the study period (Fig. 9a,c) and divided into different hydrological years (Fig. 9b,d).

\begin{tabular}{|c|c|c|c|c|c|c|c|}
\hline \multirow[b]{2}{*}{ Site } & \multirow[b]{2}{*}{ Year } & \multicolumn{2}{|c|}{$\mathrm{GPP}_{\mathrm{vpm}}=\mathrm{a} \times \mathrm{GPP}_{\mathrm{EC}}$} & \multirow{2}{*}{$\begin{array}{c}\mathrm{GPP}_{\mathrm{EC}} \\
\left(\mathrm{g} \mathrm{C} \mathrm{m}^{-2}\right)\end{array}$} & \multirow{2}{*}{$\begin{array}{l}\mathrm{GPP}_{\mathrm{vpm}} \\
\left(\mathrm{g} \mathrm{C} \mathrm{m}^{-2}\right)\end{array}$} & \multirow[t]{2}{*}{ GPP\%RE } & \multirow{2}{*}{$\begin{array}{c}\text { RMSE } \\
\left(\mathrm{g} \mathrm{C} \mathrm{m}^{-2} \text { day }^{-1}\right)\end{array}$} \\
\hline & & slope & $\mathrm{R}^{2}$ & & & & \\
\hline \multirow[t]{10}{*}{ US-Ton } & 2001-2002 & 1.05 & 0.96 & 906 & 978 & 7.9 & 0.88 \\
\hline & $2002-2003$ & 1.08 & 0.95 & 1082 & 1214 & 12.2 & 1.02 \\
\hline & 2003-2004 & 1.09 & 0.93 & 895 & 986 & 10.1 & 1.01 \\
\hline & 2004-2005 & 0.93 & 0.94 & 1319 & 1137 & -13.8 & 1.16 \\
\hline & $2005-2006$ & 0.90 & 0.94 & 1117 & 1004 & -10.1 & 0.85 \\
\hline & 2006-2007 & 1.08 & 0.93 & 1068 & 1172 & 9.8 & 1.08 \\
\hline & $2007-2008$ & 1.07 & 0.93 & 822 & 885 & 7.7 & 0.85 \\
\hline & 2008-2009 & 0.91 & 0.93 & 1023 & 971 & -5.1 & 0.99 \\
\hline & $2009-2010$ & 1.02 & 0.97 & 1028 & 1074 & 4.5 & 0.85 \\
\hline & $2010-2011$ & 0.96 & 0.95 & 1131 & 1062 & -6.1 & 0.86 \\
\hline
\end{tabular}




\begin{tabular}{cccccccc} 
& $2011-2012$ & 1.05 & 0.96 & 1022 & 1090 & 6.7 & 0.75 \\
ES-LMa & $2012-2013$ & 1.04 & 0.93 & 1014 & 1094 & 7.9 & 0.89 \\
& $2003-2004$ & 0.99 & 0.98 & 983 & 961 & -2.2 & 0.67 \\
$2004-2005$ & 1.09 & 0.95 & 865 & 942 & 9.0 & 0.64 \\
$2005-2006$ & 1.01 & 0.95 & 1101 & 1162 & 5.5 & 0.86 \\
$2006-2007$ & 1.01 & 0.96 & 1249 & 1141 & -8.6 & 0.86 \\
$2007-2008$ & 1.14 & 0.95 & 1062 & 1222 & 15.1 & 1.04 \\
$2008-2009$ & 0.91 & 0.97 & 873 & 804 & -7.8 & 0.58 \\
$2009-2010$ & 0.91 & 0.96 & 1328 & 1179 & -11.2 & 0.96 \\
$2010-2011$ & 0.83 & 0.93 & 1237 & 1063 & -14.0 & 1.22 \\
$2011-2012$ & 1.15 & 0.91 & 603 & 715 & 18.6 & 0.97 \\
\hline
\end{tabular}

Table 3. Linear regression coefficients (slope) and coefficients of determination $\left(\mathrm{R}^{2}\right)$, and seasonally integrated values of simulated $\left(\mathrm{GPP}_{\mathrm{vpm}}\right)$ and tower-derived $\left(\mathrm{GPP}_{\mathrm{EC}}\right)$ gross primary production for two savanna sites. Relative error in GPP sums (GPP\%RE) were calculated by $\left[\left(\mathrm{GPP}_{\mathrm{vpm}}-\mathrm{GPP}_{\mathrm{EC}}\right) / \mathrm{GPP}_{\mathrm{EC}}\right] \times 100$. RMSE is root mean square error $\left(\mathrm{g} \mathrm{C} \mathrm{m}^{-2} \mathrm{day}^{-1}\right)$.

\subsection{MODIS GPP (GPPmod) and flux tower GPP (GPP EC $)$}

Fig. 10 shows the seasonal dynamics of $\mathrm{GPP}_{\bmod }$ and $\mathrm{GPP}_{\mathrm{EC}}$ at two savanna sites. Although $\mathrm{GPP}_{\text {mod }}$ showed similar seasonal dynamics and interannual variations of $\mathrm{GPP}_{\mathrm{EC}}$, the magnitudes of $\mathrm{GPP}_{\text {mod }}$ were lower than those of $\mathrm{GPP}_{\mathrm{EC}}$ at both sites in all hydrological years. $\mathrm{GPP}_{\text {mod }}$ underestimated GPP more at the US-Ton site (slope $=0.67, \mathrm{R}^{2}=0.92$ ) than at the ES-LMa site $\left(\right.$ slope $\left.=0.78, \mathrm{R}^{2}=0.92\right)($ Table 4$)$. 


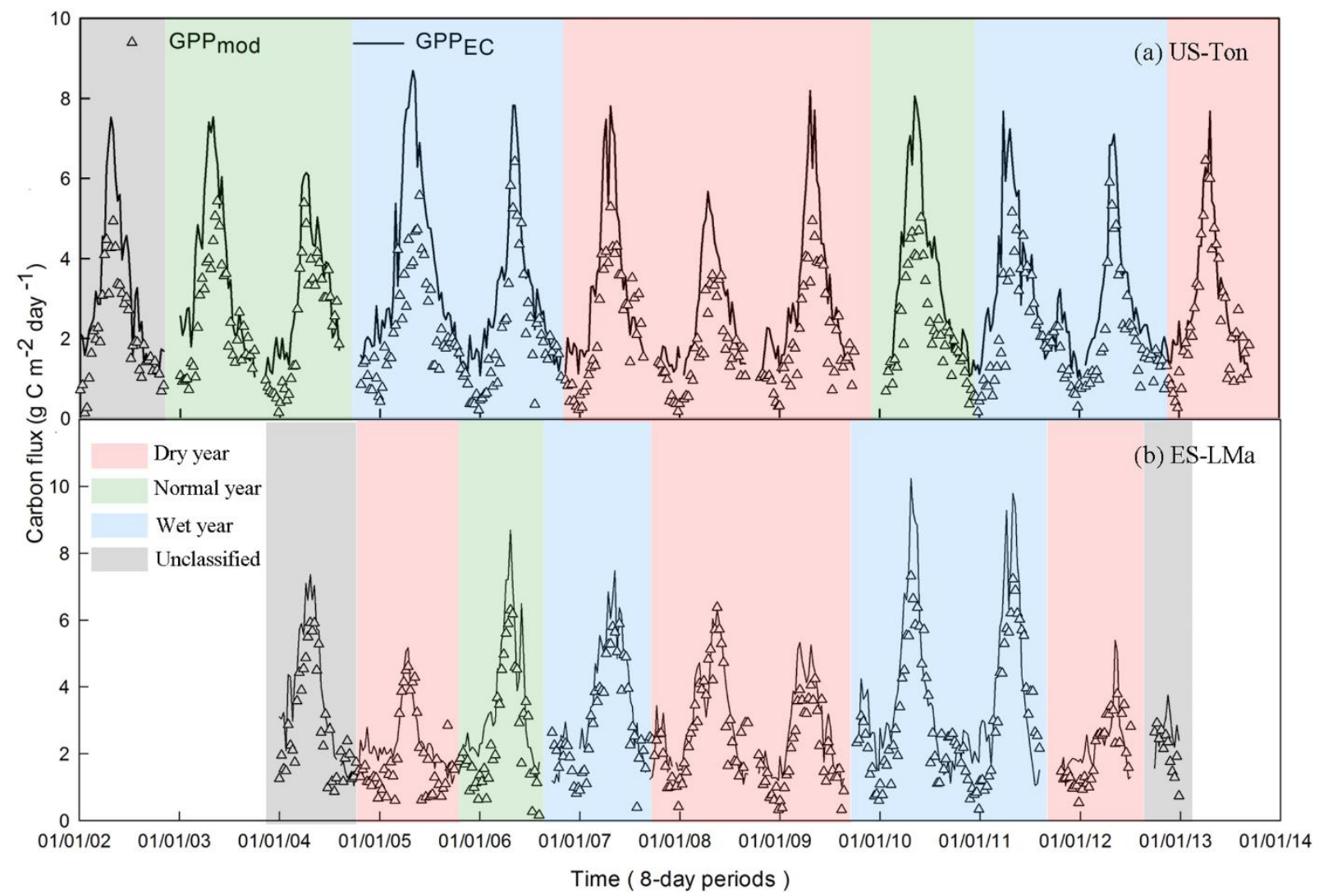

Fig. 10. Comparison of MODIS-based gross primary production $\left(\mathrm{GPP}_{\mathrm{mod}}\right)$ and tower-derived gross primary production $\left(\mathrm{GPP}_{\mathrm{EC}}\right)$ at two savanna sites.

\begin{tabular}{|c|c|c|c|c|c|c|c|}
\hline \multirow[b]{2}{*}{ Site } & \multirow[b]{2}{*}{ Year } & \multicolumn{2}{|c|}{$\mathrm{GPP}_{\text {mod }}=\mathrm{a} \times \mathrm{GPP}_{\mathrm{EC}}$} & \multirow{2}{*}{$\begin{array}{l}\mathrm{GPP}_{\mathrm{EC}} \\
\left(\mathrm{g} \mathrm{C} \mathrm{m}^{-2}\right)\end{array}$} & \multirow{2}{*}{$\begin{array}{l}\mathrm{GPP}_{\text {mod }} \\
\left(\mathrm{g} \mathrm{C} \mathrm{m}^{-2}\right)\end{array}$} & \multirow{2}{*}{$\begin{array}{c}\text { GPP\%R } \\
\text { E }\end{array}$} & \multirow{2}{*}{$\begin{array}{c}\text { RMSE } \\
\left(\mathrm{g} \mathrm{C} \mathrm{m}^{-2} \text { day }^{-1}\right)\end{array}$} \\
\hline & & slope & $\mathrm{R}^{2}$ & & & & \\
\hline \multirow[t]{12}{*}{ US-Ton } & 2001-2002 & 0.64 & 0.95 & 906 & 578 & -36.2 & 1.59 \\
\hline & $2002-2003$ & 0.64 & 0.93 & 1082 & 716 & -33.8 & 1.58 \\
\hline & 2003-2004 & 0.79 & 0.94 & 895 & 693 & -22.6 & 0.94 \\
\hline & 2004-2005 & 0.56 & 0.92 & 1319 & 751 & -43.0 & 2.23 \\
\hline & $2005-2006$ & 0.70 & 0.93 & 1117 & 743 & -33.5 & 1.22 \\
\hline & 2006-2007 & 0.68 & 0.91 & 1068 & 755 & -29.3 & 1.38 \\
\hline & $2007-2008$ & 0.63 & 0.92 & 822 & 518 & -37.0 & 1.22 \\
\hline & 2008-2009 & 0.63 & 0.94 & 1023 & 650 & -36.5 & 1.47 \\
\hline & $2009-2010$ & 0.61 & 0.96 & 1028 & 650 & -36.7 & 1.90 \\
\hline & $2010-2011$ & 0.64 & 0.86 & 1131 & 754 & -33.4 & 1.64 \\
\hline & 2011-2012 & 0.72 & 0.95 & 1022 & 714 & -30.2 & 1.05 \\
\hline & $2012-2013$ & 0.87 & 0.95 & 1014 & 851 & -16.1 & 0.77 \\
\hline
\end{tabular}




\begin{tabular}{cccccccc} 
& All years & 0.67 & 0.92 & & & \\
ES-LMa & $2003-2004$ & 0.74 & 0.96 & 983 & 715 & -27.2 & 1.32 \\
& $2004-2005$ & 0.81 & 0.89 & 865 & 672 & -22.2 & 0.85 \\
$2005-2006$ & 0.74 & 0.91 & 1101 & 821 & -25.4 & 1.35 \\
$2006-2007$ & 0.81 & 0.95 & 1249 & 1017 & -18.6 & 1.02 \\
$2007-2008$ & 0.91 & 0.94 & 1062 & 976 & -8.1 & 0.82 \\
$2008-2009$ & 0.76 & 0.95 & 873 & 655 & -25.0 & 0.89 \\
$2009-2010$ & 0.75 & 0.95 & 1328 & 993 & -25.2 & 1.39 \\
$2010-2011$ & 0.79 & 0.90 & 1237 & 1054 & -14.8 & 1.47 \\
$2011-2012$ & 0.84 & 0.87 & 603 & 527 & -12.5 & 0.88 \\
All years & 0.78 & 0.92 & & & & \\
\hline
\end{tabular}

Table 4. Linear regression coefficients (slope and coefficients of determination, $\mathrm{R}^{2}$ ), seasonally integrated values of MODIS-based gross primary production $\left(\mathrm{GPP}_{\bmod }\right)$ and tower-derived GPP $\left(\mathrm{GPP}_{\mathrm{EC}}\right)$ for two savanna sites.

\section{Discussion}

\subsection{Seasonality of VIs, GPP EC $_{\text {and savanna phenology }}$}

The deciduous savanna at the US-Ton site consists of four phenological stages for grasses and trees (Ma et al., 2007). Annual grasses germinate following the first autumn rainfall and grow slowly during the winter, grow and develop rapidly in the spring, and then die before the onset of the dry summer. Oak leaves emerge at the end of March and stay photosynthetically active during the summer, and fall down in the autumn and winter (Bartolome, 1979; Ma et al., 2007; Xu and Baldocchi, 2003). The savanna at the ES-LMa site is composed of evergreen holm oak trees and annual grasses. Holm oak trees emerge new leaves in spring and may have a weak leaf flushing in the autumn (Vaz et al., 2010; Wingate et al., 2015). The annual grasses also germinate after the autumn rains and die by the end of May, having a growing season of October to May (Casals et al., 2009; Figueroa and Davy, 1991). VIs and $\mathrm{GPP}_{\mathrm{EC}}$ at the US-Ton site increased slowly in the autumn and winter (Fig.4 and Fig.7), which can be attributed to the green up of the herbaceous layer (60\% coverage). Comparing the VIs and $\mathrm{GPP}_{\mathrm{EC}}$ in the autumn and 
winter with those in the dry summer also revealed the contributions of the herbaceous layer $(80 \%$ coverage) to the seasonal dynamics of VIs and $\mathrm{GPP}_{\mathrm{EC}}$ at the ES-LMa site. Assessment of the relative effects of tree layer and herbaceous layer could explain the influence of the savanna structure on carbon dynamics, which was not performed in this study due to the lack of separately ground-based observations of seasonality of VIs and GPP of trees and grasses.

\subsection{Responses of two savannas to variations in annual precipitation}

Our results show that interannual variations in precipitation influenced VIs and $\mathrm{GPP}_{\mathrm{EC}}$ more at the evergreen savanna (ES-LMa) site than at the deciduous savanna (US-Ton) site. For example, Fig. $4 d$ shows that a substantial reduction in $\mathrm{GPP}_{\mathrm{EC}}$ only occurred in a few dry or normal years with low annual precipitation (2003-2004 and 2007-2008) at the US-Ton site, while at the ES-LMa site, it occurred in all dry years (2004-2005, 2007-2008, 2008-2009, and 2011-

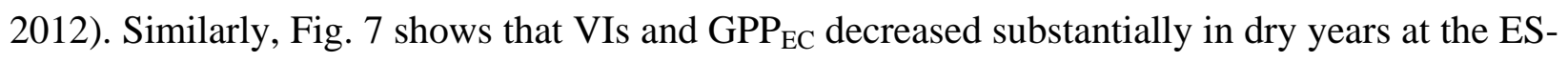
LMa site, but not at the US-Ton site. A meta-analysis for Mediterranean oak woodlands also showed that deciduous oak savannas were more resilient to drought and evergreen oak savannas were more sensitive to drought, as seen by a substantial reduction in ecosystem flux during drought (Vargas et al., 2013). Different tree canopy covers between two sites could be a possible reason for differences in responses of two savannas to precipitation. In savannas, grasses draw the upper soil water with shallow roots. This supply is exhausted quickly by grasses with high rate of transpiration (Walker and Noymeir, 1982). Trees access to the deeper soil water with deep roots. This water source support trees living through the dry seasons (Walker and Noymeir, 1982). Tress can also use the percolating water from the upper layer soil which is unused by grasses (Eagleson and Segarra, 1985). As well as, trees improve the soil nutrients and waterholding capacity, and control the water use of the understory vegetation by changing the 
microclimate (Jackson et al., 1990; Joffre and Rambal, 1993; Scholes and Archer, 1997). Studies of the Mediterranean savannas showed that tree canopies improved the soil water storage and alleviated the water stress on vegetation in the ecosystem (Joffre and Rambal, 1993; Joffre et al., 1999). The deciduous savanna at the US-Ton site has higher tree canopy cover (about 40\%) than that (about 20\%) of the evergreen savanna at the ES-LMa site. Thus, higher tree cover could reduce the sensitivity of the US-Ton savanna to the water stress caused by the variations in precipitation. In Mediterranean ecosystems, plant photosynthesis is mostly limited by soil water availability (Gilabert et al., 2015; Niinemets and Keenan, 2014; Nijland et al., 2011; Xu and Baldocchi, 2004). Soil moisture availability was controlled by rainfall, soil properties, and geomorphology (Eagleson and Segarra, 1985). Differences in soil hydrological properties (i.e., SWC, Fig. 3c) may be another possible reason for the different responses of these two savannas

to precipitation changes. A modeling study on grassland ecosystems demonstrated that soil available water capacity can alter the partitioning of precipitation and influence the buffer of water stress during long drought periods (Weng and Luo, 2008). As vegetation responses to precipitation are complicated at ecosystem scales, further studies of Mediterranean-climate savannas are needed to explore the mechanisms at different spatial and temporal scales.

\subsection{Model comparison}

At these two savanna sites, $\mathrm{GPP}_{\mathrm{vpm}}$ showed good agreement with $\mathrm{GPP}_{\mathrm{EC}}$, and GPPmod was lower than $\mathrm{GPP}_{\mathrm{EC}}$ in all years (Fig. 9, Fig. 10). The underestimations of $\mathrm{GPP}_{\mathrm{mod}}$ have been reported in other biomes such as the African savanna (Jin et al., 2013; Sjöström et al., 2013), deciduous forests (Wu et al., 2010), and grasslands (Wagle et al., 2014). Previous studies have shown that the discrepancies between $\mathrm{GPP}_{\mathrm{mod}}$ and $\mathrm{GPP}_{\mathrm{EC}}$ are mainly due to estimation errors of 
LUE in those models (Sims et al., 2008; Sims et al., 2006). The $\varepsilon_{0}$ value used in this study was about $0.5 \mathrm{~g} \mathrm{C} / \mathrm{mol}$ PAR $\left(\sim 1.04 \mathrm{~g} \mathrm{C} \mathrm{MJ}^{-1}\right)$. This value is almost the same as that of $1.03 \mathrm{~g} \mathrm{C} \mathrm{MJ}^{-1}$ for savannas used by the MOD17A2 product in Collection 5.0 (Kanniah et al., 2009) and lower than $1.21 \mathrm{~g} \mathrm{C} \mathrm{MJ}^{-1}$ used in Collections 5.1 and 6 (Running and Zhao, 2015; Sjöström et al., 2013; Zhao and Running, 2010). This value is also lower than the maximum LUE inferred by the site specific estimations in tropical savannas, such as $1.26 \pm 0.03 \mathrm{~g} \mathrm{C} \mathrm{MJ}^{-1}$ (Kanniah et al., 2009) in Northern Australia and $1.66 \mathrm{~g} \mathrm{C} \mathrm{MJ}^{-1}$ in Africa (Sjöström et al., 2013). This comparison showed

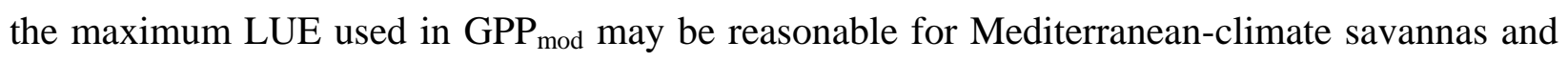
other factors should be examined to explain the underestimation of GPP ${ }_{\text {mod. }}$

Another simple way to compare simulations of GPP models is to evaluate (1) the length of plant phenology and (2) maximum GPP value in plant growing season. Recent studies shows that annual GPP can be explained by the integrated controls of plant phenology (Carbon Uptake Period (CUP)) and physiological processes (seasonal maximal capacity of $\mathrm{CO}_{2}$ uptake, $\mathrm{GPP}_{\max }$ ) (Wagle et al., 2015a; Wagle et al., 2015b; Xia et al., 2015). As the CUP (number of days of carbon uptake by the ecosystem) term is generally used for analysis of NEE data (Churkina et al., 2005; Wagle et al., 2015a), here we use Active Photosynthesis Period (APP) for analysis of GPP data, and APP is defined as the period of daily GPP $>=1 \mathrm{~g} \mathrm{C} \mathrm{m}^{2} \mathrm{~d}^{-1}$. We compared the interannual dynamics of $\mathrm{APP}$ and $\mathrm{GPP}_{\max }$ estimated from EC ( $\left.\mathrm{APP}_{\mathrm{EC}}, \mathrm{GPP}_{\max \_\mathrm{EC}}\right)$, VPM $\left(\mathrm{APP}_{\mathrm{VPM}}, \mathrm{GPP}_{\text {max }_{\mathrm{V}} \mathrm{VPM}}\right)$, and the standard MODIS GPP product ( $\left.\mathrm{APP}_{\text {mod, }} \mathrm{GPP}_{\text {max_mod }}\right)$ at these two savanna sites, respectively (Fig. 11). Fig. 11a,b show that $\mathrm{APP}_{\text {mod }}$ was significantly shorter than $\mathrm{APP}_{\mathrm{EC}}$, and $\mathrm{GPP}_{\text {max_mod }}$ was much lower than $\mathrm{GPP}_{\max \_\mathrm{EC}}$. $\mathrm{APP}_{\mathrm{VPM}}$ and $\mathrm{GPP}_{\max \_\mathrm{VPM}}$ were more comparable with $\mathrm{APP}_{\mathrm{EC}}$ and $\mathrm{GPP}_{\text {max_EC. }}$. The simple linear regression analyses show that at these two savanna sites, the ratio $\alpha$ (slope in the linear regression model) between annual GPP 
(including $\mathrm{GPP}_{\mathrm{EC}}, \mathrm{GPP}_{\mathrm{mod}}$ and $\mathrm{GPP}_{\mathrm{VPM}}$ ) and the product of $\mathrm{APP} \times \mathrm{GPPmax}$ over years ranges from 0.43 to 0.52 (Fig. 11c), which is much lower than the value of $\alpha=0.68$ reported for the savanna sites by Xia et al. (2015).
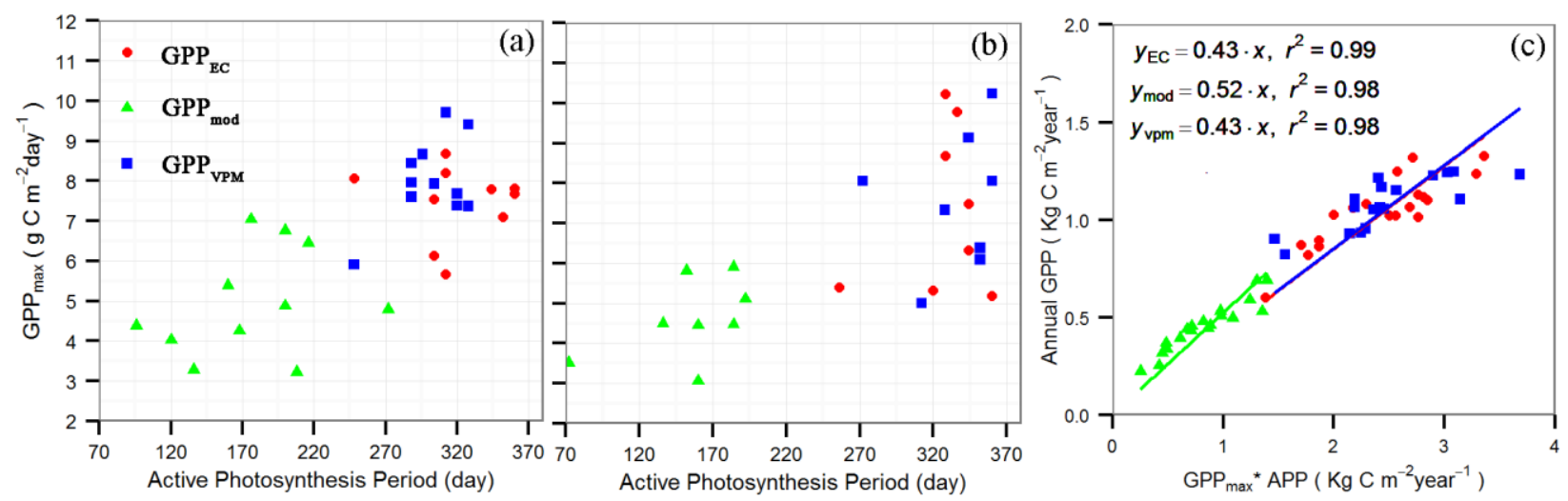

Fig. 11. Comparison of active photosynthesis period (APP) and the annual maximum gross primary production $\left(\mathrm{GPP}_{\max }\right)$ estimated from tower-derived gross primary production $\left(\mathrm{GPP}_{\mathrm{EC}}\right)$, MODIS-based gross primary production $\left(\mathrm{GPP}_{\mathrm{mod}}\right)$ and simulated GPP by vegetation photosynthesis model $\left(\mathrm{GPP}_{\mathrm{vpm}}\right)$ at two savannas sites (Fig. 11a for US-Ton site; Fig. 11b for ESLMa site). Fig. 11c shows the relationship between annual GPP (including GPP EC $_{\text {, GPP }}$ mod and $\mathrm{GPP}_{\mathrm{VPM}}$ ) and the product of GPP $\mathrm{max}_{\text {ax }}$ and at two savanna sites.

\subsection{Parameter estimation in the VPM model}

This study proposed an approach to estimate the $\mathrm{T}_{\mathrm{opt}}$ at ecosystem level. We demonstrated

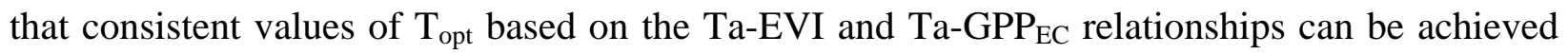
by excluding the influence of water stress on EVI and $\mathrm{GPP}_{\mathrm{EC}}$ in dry years (i.e., using data only from wet years instead of all years, Fig. 6). It follows the assumption that maximum EVI and $\mathrm{GPP}_{\mathrm{EC}}$ values represent optimal growth conditions (Singh et al., 2003; Yang et al., 2013). $\mathrm{T}_{\mathrm{opt}}$ for photosynthesis varies widely with species at leaf and canopy scales (Baldocchi et al., 2001; Medlyn et al., 2002). At the site or ecosystem scales, a specific $\mathrm{T}_{\mathrm{opt}}$ may not be applicable to all sites and various growth conditions, especially for savannas with various canopy proportions (Cui, 2013; Sims et al., 2008). Considering the influence of water stress on VIs for the estimation of $\mathrm{T}_{\mathrm{opt}}$ may improve the model's performance, as the maximum NDVI values are used to 
estimate the optimal weather at ecosystem scale (Singh et al., 2003) and $\mathrm{T}_{\mathrm{opt}}$ is used in processbased and LUE-based GPP models (Raich et al., 1991; Tao et al., 2005; Yang et al., 2013). Topt for photosynthesis of Mediterranean plants ranged from $15^{\circ} \mathrm{C}$ to $30^{\circ} \mathrm{C}$ according to the studies under controlled conditions, and Mediterranean trees had higher Topt $\left(\sim 22^{\circ} \mathrm{C}\right)$ than $\operatorname{did} \mathrm{C}_{3}$ grasses (Charles-Edwards et al., 1971; Larcher, 2000; Ogaya and Penuelas, 2003). Both savanna sites are mixed ecosystems of $\mathrm{C}_{3}$ grasses and trees, with tree coverage of $40 \%$ at the US-Ton site and $20 \%$ at the ES-LMa site. Our analysis showed that Topt was $18{ }^{\circ} \mathrm{C}$ at the US-Ton site and 14 ${ }^{\circ} \mathrm{C}$ at the ES-LMa site. This result is reasonable based on the Topt of Mediterranean trees and $\mathrm{C}_{3}$ grasses, and the ecosystem structures of these two savanna sites. This result is consistent with the Topt range of $10-20{ }^{\circ} \mathrm{C}$ for photosynthesis of Mediterranean plants under field conditions (Flexas et al., 2014). More studies are required to evaluate our Topt estimation approach in other terrestrial ecosystems.

The seasonal dynamics of VIs showed some differences at two sites (Fig. 4) and the US-Ton site had better correlation between $\mathrm{GPP}_{\mathrm{EC}}$ and NDVI/EVI compared to the ES-LMa site (Fig. 5). However, $\mathrm{GPP}_{\mathrm{VPM}}$ were comparable with $\mathrm{GPP}_{\mathrm{EC}}$ at both sites (Fig. 9). To further investigate the agreement of GPP, we compared observed and simulated GPP and each parameter of VPM at both sites (Fig. 12) by selecting a period from Sept. 2005 to Jun. 2006. During this period, two sites showed significantly different VIs seasonality and consistent GPP seasonality (Fig. 4). Although EVI of the ES-LMa site was higher than that of the US-Ton site from winter to the following spring (Fig. 12b), low radiation and temperature (Fig. 12c,d,e) at this time severely reduced the GPP of both sites (Fig. 12a). Therefore, similar seasonal dynamics of PAR and air temperature at the study sites resulted in occurrence of peak GPP almost at the same time (late April or early May) (Fig. 12a). Some studies reported radiation as a critical driver of GPP in 
tropical savannas (Whitley et al., 2011), but further study is needed to partition the individual effects of PAR and temperature on GPP seasonal dynamics in Mediterranean-climate savannas.

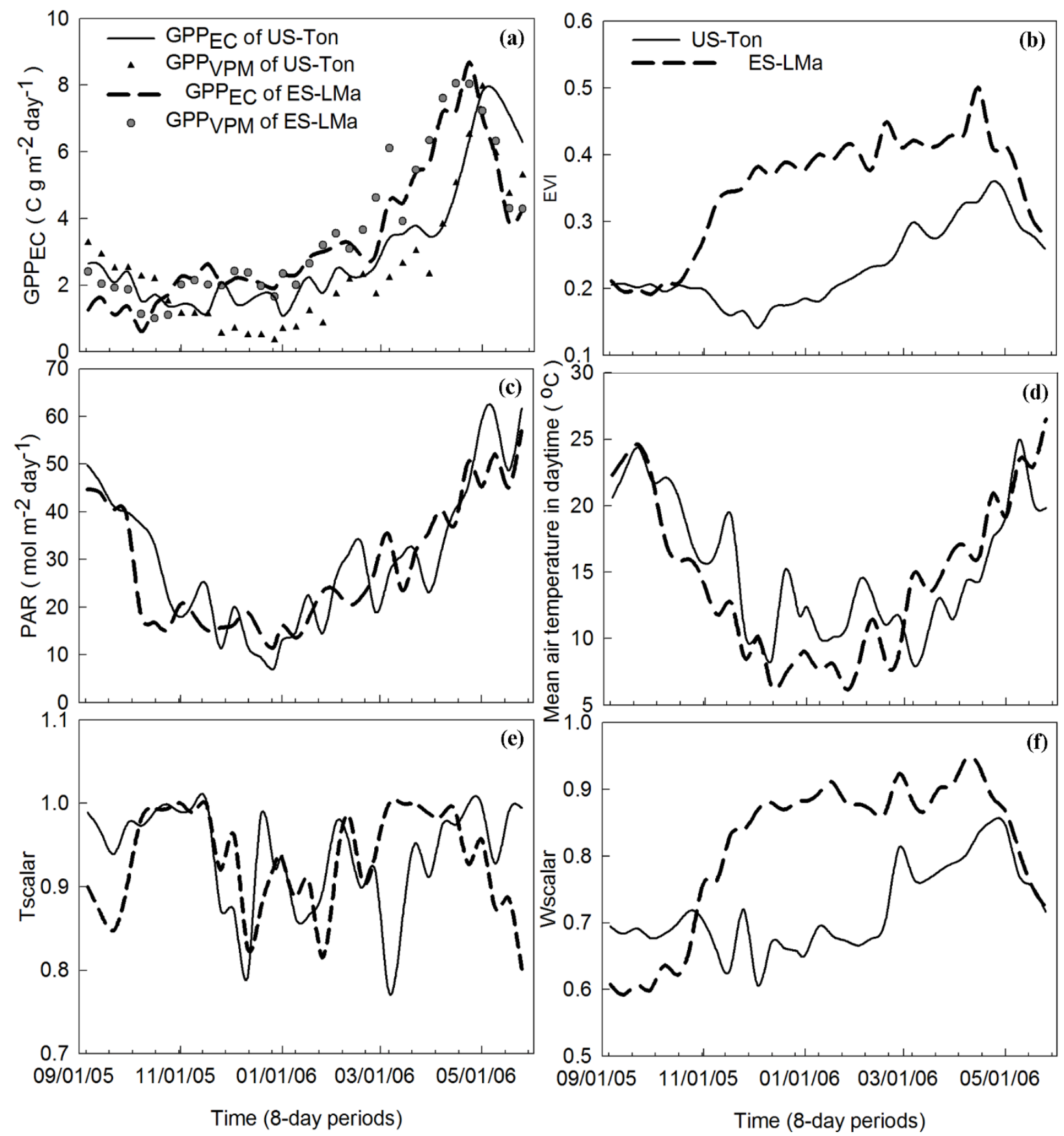

Fig. 12. Comparison of the seasonal dynamics of tower-derived gross primary production $\left(\mathrm{GPP}_{\mathrm{EC}}\right)$ and simulated GPP $\left(\mathrm{GPP}_{\mathrm{vpm}}\right)$, enhanced vegetation index (EVI), photosynthetically active radiation (PAR), mean daytime air temperature, and temperature and water scalars in vegetation photosynthesis model (VPM) for the period of Sept.2005-Jun. 2006 at two savanna sites. 
In addition, we examined the relative contributions of the water scalar and temperature scalar to the simulation of GPP (physiological process) at these savannas under different hydrological years. Fig. 13 compares $\mathrm{GPP}_{\mathrm{EC}}, \mathrm{GPP}_{\mathrm{vpm}}$, and $\mathrm{GPP}_{\mathrm{vpm}}$ without $\mathrm{T}_{\text {scalar }}$ and $\mathrm{W}_{\text {scalar }}$. The results show that VPM slightly overestimated GPP in the green-up (or initial growth) stage without $\mathrm{T}_{\text {scalar }}$ or $\mathrm{W}_{\text {scalar }}$ at both sites, but substantially overestimated GPP in the peak growth and senescence periods. These results suggest that it is essential to incorporate both $\mathrm{W}_{\text {scalar }}$ and $\mathrm{T}_{\text {scalar }}$ in VPM regardless of dry or wet hydrological years. However, GPP simulation is more sensitive to $\mathrm{W}_{\text {scalar }}$ than to $\mathrm{T}_{\text {scalar }}$ at these savanna sites. The effect of water status on plant physiological processes such as photosynthesis (GPP) can be represented in model by soil water content (indicator of water supply from the soils), or atmospheric vapor pressure deficit (indicator of atmospheric water demand and stomatal regulation), or plant leaf/canopy water content (indicator of plant health and stomatal control) (Xiao et al., 2004). As an observation-based diagnostic biogeochemical model, the VPM uses LSWI, which is sensitive to water content in leaf/canopy/land surface, to approximate the effect of water on GPP (Xiao et al., 2004, 2005). Previous studies showed that LSWI and LSWI-based Wscalar were sensitive to droughts in croplands and tallgrass prairie (Dong et al., 2015; Potter et al., 1993; Wagle et al., 2014; Wagle et al., 2015b). Although there are trade-offs between soil water, meteorology (e.g., vapor pressure deficit), and canopy-based (e.g., vegetation indices) parameters in satellite-based GPP models (Gitelson et al., 2006; Sims et al., 2008; Yang et al., 2013), our results illustrate the potential of VPM to simulate multi-year GPP using vegetation canopy characteristics (e.g., EVI and LSWI) and climate variables (e.g., PAR and temperature) for savannas (a mixture of tree and grass with low and dynamic LAI and high gap canopies) in the Mediterranean climate. 


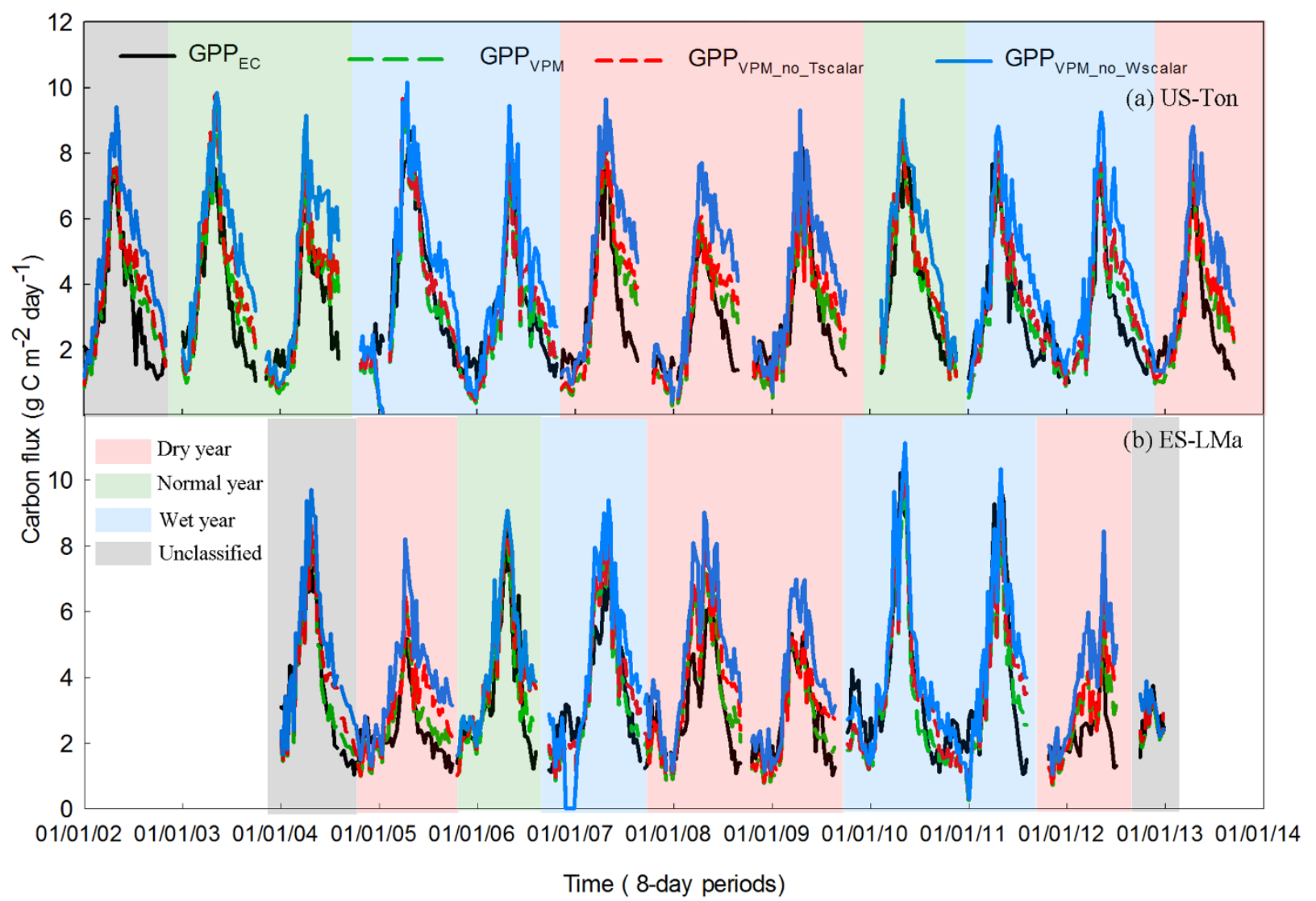

Fig. 13. Comparison of simulation scenarios: (1) Vegetation Photosynthesis Model (VPM) with both $\mathrm{T}_{\text {scalar }}$ and $\mathrm{W}_{\text {scalar }}\left(\mathrm{GPP}_{\mathrm{vpm}}\right)$, (2) VPM without $\mathrm{T}_{\text {scalar }}\left(\mathrm{GPP}_{\mathrm{vpm} \text { _no_Tscalar }}\right)$, and (3) VPM without $\mathrm{W}_{\text {scalar }}\left(\mathrm{GPP}_{\mathrm{vpm} \_n o \_W s c a l a r}\right)$.

\section{Conclusions}

This study compared the seasonal dynamics of climate, VIs, and $\mathrm{GPP}_{\mathrm{EC}}$, and their interactions at two dominant functional oak savannas (deciduous and evergreen) under the Mediterranean climate. GPP simulation of these savannas is challenging because these ecosystems experience large variations in seasonal and interannual rainfall and soil moisture, and they have sparse trees with open canopies and low LAI. We used VPM to simulate multi-year GPP under various hydrological conditions (dry, normal, and wet years) and evaluated its performance by comparing the simulations with $\mathrm{GPP}_{\mathrm{EC}}$ and the MODIS GPP product. This study demonstrates that the two savannas had similar seasonal dynamics of climate and $\mathrm{GPP}_{\mathrm{EC}}$ despite 
different VI seasonal dynamics. EVI and $\mathrm{GPP}_{\mathrm{EC}}$ had similar responses to daytime mean air temperature at both savanna sites. VIs and $\mathrm{GPP}_{\mathrm{EC}}$ of the ES-LMa site (evergreen savanna) were more sensitive to precipitation variation from dry years to wet years than those of the US-Ton site (deciduous savanna). VPM simulated seasonal dynamics and interannual variations of GPP reasonably well at both savanna sites in all hydrological conditions. The results of this study highlight the potential of integrating both EC technique and satellite remote sensing for better understanding and managing savanna ecosystems under the Mediterranean climate.

\section{Acknowledgements}

This study was supported in part by a research grant (Project No. 2012-02355) through the USDA National Institute for Food and Agriculture (NIFA)'s Agriculture and Food Research Initiative (AFRI), Regional Approaches for Adaptation to and Mitigation of Climate Variability and Change, and US National Science Foundation EPSCoR (IIA-1301789). We thank Sarah Xiao at Yale University for English editing of the manuscript.

\section{Reference:}

Bajgain, R., Xiao, X., Wagle, P., Basara, J. and Zhou, Y., 2015. Sensitivity analysis of vegetation indices to drought over two tallgrass prairie sites. Isprs J Photogramm, 108: 151-160.

Baldocchi, D. et al., 2010. The dynamics of energy, water, and carbon fluxes in a blue oak (Quercus douglasii) savanna in California. Ecosystem Function in Savannas: 135-154.

Baldocchi, D. et al., 2001. FLUXNET: A new tool to study the temporal and spatial variability of ecosystem-scale carbon dioxide, water vapor, and energy flux densities. B Am Meteorol Soc, 82(11): 2415-2434.

Bartolome, J.W., 1979. Germination and seedling establishment in California annual grassland. The Journal of Ecology: 273-281.

Bugalho, M.N., Caldeira, M.C., Pereira, J.S., Aronson, J. and Pausas, J.G., 2011. Mediterranean cork oak savannas require human use to sustain biodiversity and ecosystem services. Frontiers in Ecology and the Environment, 9(5): 278-286.

Casals, P., Gimeno, C., Carrara, A., Lopez-Sangil, L. and Sanz, M., 2009. Soil CO2 efflux and extractable organic carbon fractions under simulated precipitation events in a Mediterranean Dehesa. Soil Biology and Biochemistry, 41(9): 1915-1922.

Chang, T.J. and Kleopa, X.A., 1991. A Proposed Method for Drought Monitoring. Water Resour Bull, 27(2): 275281 . 
Charles-Edwards, D., Charles-Edwards, J. and Cooper, J., 1971. The influence of temperature on photosynthesis and transpiration in ten temperate grass varieties grown in four different environments. Journal of Experimental Botany, 22(3): 650-662.

Churkina, G., Schimel, D., Braswell, B.H. and Xiao, X., 2005. Spatial analysis of growing season length control over net ecosystem exchange. Global Change Biol, 11(10): 1777-1787.

Correia, A. et al., 2014. Carbon sink strength of a Mediterranean cork oak understorey: how do semi - deciduous and evergreen shrubs face summer drought? J Veg Sci, 25(2): 411-426.

Cui, Y.P., 2013. Preliminary Estimation of the Realistic Optimum Temperature for Vegetation Growth in China. Environ Manage, 52(1): 151-162.

Dong, J. et al., 2015. Comparison of four EVI-based models for estimating gross primary production of maize and soybean croplands and tallgrass prairie under severe drought. Remote Sens Environ, 162: 154-168.

Eagleson, P.S. and Segarra, R.I., 1985. Water-Limited Equilibrium of Savanna Vegetation Systems. Water Resources Research, 21(10): 1483-1493.

Figueroa, M. and Davy, A., 1991. Response of Mediterranean grassland species to changing rainfall. The Journal of Ecology: 925-941.

Gao, X. and Giorgi, F., 2008. Increased aridity in the Mediterranean region under greenhouse gas forcing estimated from high resolution simulations with a regional climate model. Global and Planetary Change, 62(3): 195209.

Gilabert, M.A. et al., 2015. Daily GPP estimates in Mediterranean ecosystems by combining remote sensing and meteorological data. Isprs J Photogramm, 102(0): 184-197.

Gitelson, A.A. et al., 2006. Relationship between gross primary production and chlorophyll content in crops: Implications for the synoptic monitoring of vegetation productivity. J Geophys Res-Atmos, 111(D8).

Goetz, S.J., Prince, S.D., Goward, S.N., Thawley, M.M. and Small, J., 1999. Satellite remote sensing of primary production: an improved production efficiency modeling approach. Ecol Model, 122(3): 239-255.

Heim, R.R., 2002. A review of twentieth-century drought indices used in the United States. B Am Meteorol Soc, 83(8): 1149-1165.

Hertig, E. and Jacobeit, J., 2008. Downscaling future climate change: Temperature scenarios for the Mediterranean area. Global and Planetary Change, 63(2): 127-131.

Hilker, T., Coops, N.C., Wulder, M.A., Black, T.A. and Guy, R.D., 2008. The use of remote sensing in light use efficiency based models of gross primary production: A review of current status and future requirements. Sci Total Environ, 404(2-3): 411-423.

Huete, A. et al., 2002. Overview of the radiometric and biophysical performance of the MODIS vegetation indices. Remote Sens Environ, 83(1-2): 195-213.

Huete, A.R., Liu, H.Q., Batchily, K. and vanLeeuwen, W., 1997. A comparison of vegetation indices over a global set of TM images for EOS-MODIS. Remote Sensing of Environment, 59(3): 440-451.

Jackson, L.E., Strauss, R.B., Firestone, M.K. and Bartolome, J.W., 1990. Influence of Tree Canopies on Grassland Productivity and Nitrogen Dynamics in Deciduous Oak Savanna. Agr Ecosyst Environ, 32(1-2): 89-105.

Jin, C. et al., 2013. Phenology and gross primary production of two dominant savanna woodland ecosystems in Southern Africa. Remote Sens Environ, 135: 189-201.

Joffre, R. and Rambal, S., 1993. How Tree Cover Influences the Water-Balance of Mediterranean Rangelands. Ecology, 74(2): 570-582.

Joffre, R., Rambal, S. and Ratte, J.P., 1999. The dehesa system of southern Spain and Portugal as a natural ecosystem mimic. Agroforestry Systems, 45(1-3): 57-79.

Kalfas, J.L., Xiao, X., Vanegas, D.X., Verma, S.B. and Suyker, A.E., 2011. Modeling gross primary production of irrigated and rain-fed maize using MODIS imagery and CO2 flux tower data. Agr Forest Meteorol.

Kanniah, K., Beringer, J., Hutley, L., Tapper, N. and Zhu, X., 2009. Evaluation of Collections 4 and 5 of the MODIS Gross Primary Productivity product and algorithm improvement at a tropical savanna site in northern Australia. Remote Sens Environ, 113(9): 1808-1822.

Kobayashi, H., Ryu, Y., Baldocchi, D.D., Welles, J.M. and Norman, J.M., 2013. On the correct estimation of gap fraction: How to remove scattered radiation in gap fraction measurements? Agr Forest Meteorol, 174: 170183.

Larcher, W., 2000. Temperature stress and survival ability of Mediterranean sclerophyllous plants. Plant Biosyst, 134(3): 279-295.

Ma, S., Baldocchi, D.D., Xu, L. and Hehn, T., 2007. Inter-annual variability in carbon dioxide exchange of an oak/grass savanna and open grassland in California. Agr Forest Meteorol, 147(3-4): 157-171. 
Marañón, T., Pugnaire, F.I. and Callaway, R.M., 2009. Mediterranean-climate oak savannas: the interplay between abiotic environment and species interactions. Web Ecology, 9: 30-43.

McKee, T.B., Doesken, N.J. and Kleist, J., 1993. The relationship of drought frequency and duration to time scales, Proceedings of the 8th Conference on Applied Climatology. American Meteorological Society Boston, MA, USA, pp. 179-183.

Medlyn, B. et al., 2002. Temperature response of parameters of a biochemically based model of photosynthesis. II. A review of experimental data. Plant, Cell \& Environment, 25(9): 1167-1179.

Monteith, J.L., 1972. Solar Radiation and Productivity in Tropical Ecosystems. J. Appl. Ecol., 9(3): 747-766.

Niinemets, Ü. and Keenan, T., 2014. Photosynthetic responses to stress in Mediterranean evergreens: mechanisms and models. Environmental and Experimental Botany, 103: 24-41.

Nijland, W., Jansma, E., Addink, E., Domínguez Delmás, M. and De Jong, S., 2011. Relating ring width of Mediterranean evergreen species to seasonal and annual variations of precipitation and temperature. Biogeosciences Discussions, 8(1): 355-383.

Ogaya, R. and Penuelas, J., 2003. Comparative seasonal gas exchange and chlorophyll fluorescence of two dominant woody species in a Holm Oak Forest. Flora, 198(2): 132-141.

Palmer, W.C., 1965. Meteorological Drought, Weather Bureau, Washington, D. C., pp. 55.

Potter, C.S. et al., 1993. Terrestrial Ecosystem Production - a Process Model-Based on Global Satellite and Surface Data. Glob. Biogeochem. Cycle, 7(4): 811-841.

Raich, J. et al., 1991. Potential net primary productivity in South America: application of a global model. Ecol Appl: 399-429.

Ruimy, A., Kergoat, L., Bondeau, A. and Intercomparison, P.P.N.M., 1999. Comparing global models of terrestrial net primary productivity (NPP): analysis of differences in light absorption and light-use efficiency. Global Change Biol, 5: 56-64.

Running, S.W. et al., 2004. A continuous satellite-derived measure of global terrestrial primary production. Bioscience, 54(6): 547-560.

Running, S.W. and Zhao, M., 2015. Daily GPP and Annual NPP (MOD17A2/A3) Products NASA Earth Observing System MODIS Land Algorithm.

Ryu, Y. et al., 2010. How to quantify tree leaf area index in an open savanna ecosystem: A multi-instrument and multi-model approach. Agr Forest Meteorol, 150(1): 63-76.

Scholes, R. and Archer, S., 1997. Tree-grass interactions in savannas. Annual review of Ecology and Systematics: 517-544.

Sims, D.A. et al., 2008. A new model of gross primary productivity for North American ecosystems based solely on the enhanced vegetation index and land surface temperature from MODIS. Remote Sens Environ, 112(4): 1633-1646.

Sims, D.A. et al., 2006. On the use of MODIS EVI to assess gross primary productivity of North American ecosystems. J Geophys Res-Biogeo, 111(G4).

Singh, R.P., Roy, S. and Kogan, F., 2003. Vegetation and temperature condition indices from NOAA AVHRR data for drought monitoring over India. Int J Remote Sens, 24(22): 4393-4402.

Sjöström, M. et al., 2013. Evaluation of MODIS gross primary productivity for Africa using eddy covariance data. Remote Sens Environ, 131: 275-286.

Tao, F., Yokozawa, M., Zhang, Z., Xu, Y. and Hayashi, Y., 2005. Remote sensing of crop production in China by production efficiency models: models comparisons, estimates and uncertainties. Ecol Model, 183(4): 385396.

Tucker, C.J., 1979. Red and photographic infrared linear combinations for monitoring vegetation. Remote Sensing of Environment, 8(2): 127-150.

Turner, D.P. et al., 2006. Evaluation of MODIS NPP and GPP products across multiple biomes. Remote Sens Environ, 102(3-4): 282-292.

Vargas, R. et al., 2013. Drought Influences the Accuracy of Simulated Ecosystem Fluxes: A Model-Data Metaanalysis for Mediterranean Oak Woodlands. Ecosystems, 16(5): 749-764.

Vaz, M. et al., 2010. Drought-induced photosynthetic inhibition and autumn recovery in two Mediterranean oak species (Quercus ilex and Quercus suber). Tree Physiol, 30(8): 946-956.

Veroustraete, F., Sabbe, H. and Eerens, H., 2002. Estimation of carbon mass fluxes over Europe using the C-Fix model and Euroflux data. Remote Sens Environ, 83(3): 376-399.

Vicente-Serrano, S.M., Begueria, S. and Lopez-Moreno, J.I., 2010. A Multiscalar Drought Index Sensitive to Global Warming: The Standardized Precipitation Evapotranspiration Index. Journal of Climate, 23(7): 1696-1718. 
Vicente-Serrano, S.M. et al., 2012. Performance of Drought Indices for Ecological, Agricultural, and Hydrological Applications. Earth Interactions, 16.

Wagle, P. et al., 2015a. Biophysical controls on carbon and water vapor fluxes across a grassland climatic gradient in the United States. Agr Forest Meteorol, 214-215: 293-305.

Wagle, P. et al., 2014. Sensitivity of vegetation indices and gross primary production of tallgrass prairie to severe drought. Remote Sens. Environ., 152: 1-14.

Wagle, P., Xiao, X.M. and Suyker, A.E., 2015b. Estimation and analysis of gross primary production of soybean under various management practices and drought conditions. Isprs J Photogramm, 99: 70-83.

Walker, B.H. and Noymeir, I., 1982. Aspects of the Stability and Resilience of Savanna Ecosystems. Ecol Stud, 42: 557-590.

Weng, E.S. and Luo, Y.Q., 2008. Soil hydrological properties regulate grassland ecosystem responses to multifactor global change: A modeling analysis. J Geophys Res-Biogeo, 113(G3).

Whitley, R.J. et al., 2011. Is productivity of mesic savannas light limited or water limited? Results of a simulation study. Global Change Biol, 17(10): 3130-3149.

Widlowski, J.L., 2010. On the bias of instantaneous FAPAR estimates in open-canopy forests. Agr Forest Meteorol, 150(12): 1501-1522.

Wingate, L. et al., 2015. Interpreting canopy development and physiology using a European phenology camera network at flux sites. Biogeosciences, 12(20): 5995-6015.

Wu, C.Y., Munger, J.W., Niu, Z. and Kuang, D., 2010. Comparison of multiple models for estimating gross primary production using MODIS and eddy covariance data in Harvard Forest. Remote Sens Environ, 114(12): 2925-2939.

Xia, J. et al., 2015. Joint control of terrestrial gross primary productivity by plant phenology and physiology. Proceedings of the National Academy of Sciences, 112(9): 2788-2793.

Xiao, X. et al., 2005a. Satellite-based modeling of gross primary production in a seasonally moist tropical evergreen forest. Remote Sens Environ, 94(1): 105-122.

Xiao, X.M., 2006. Light absorption by leaf chlorophyll and maximum light use efficiency. Ieee T Geosci Remote, 44(7): 1933-1935.

Xiao, X.M. et al., 2004a. Satellite-based modeling of gross primary production in an evergreen needleleaf forest. Remote Sens Environ, 89(4): 519-534.

Xiao, X.M. et al., 2004b. Modeling gross primary production of temperate deciduous broadleaf forest using satellite images and climate data. Remote Sensing of Environment, 91(2): 256-270.

Xiao, X.M., Zhang, Q.Y., Hollinger, D., Aber, J. and Moore, B., 2005b. Modeling gross primary production of an evergreen needleleaf forest using modis and climate data. Ecological Applications, 15(3): 954-969.

Xu, L. and Baldocchi, D.D., 2004. Seasonal variation in carbon dioxide exchange over a Mediterranean annual grassland in California. Agr Forest Meteorol, 123(1): 79-96.

Xu, L.K. and Baldocchi, D.D., 2003. Seasonal trends in photosynthetic parameters and stomatal conductance of blue oak (Quercus douglasii) under prolonged summer drought and high temperature. Tree Physiol, 23(13): 865877.

Yang, Y., Shang, S., Guan, H. and Jiang, L., 2013. A novel algorithm to assess gross primary production for terrestrial ecosystems from MODIS imagery. Journal of Geophysical Research: Biogeosciences, 118(2): 590-605.

Yuan, W.P. et al., 2007. Deriving a light use efficiency model from eddy covariance flux data for predicting daily gross primary production across biomes. Agr Forest Meteorol, 143(3-4): 189-207.

Zhao, M. and Running, S.W., 2010. Drought-Induced Reduction in Global Terrestrial Net Primary Production from 2000 Through 2009. Science, 329(5994): 940-943.

Zhao, M.S., Heinsch, F.A., Nemani, R.R. and Running, S.W., 2005. Improvements of the MODIS terrestrial gross and net primary production global data set. Remote Sens Environ, 95(2): 164-176. 


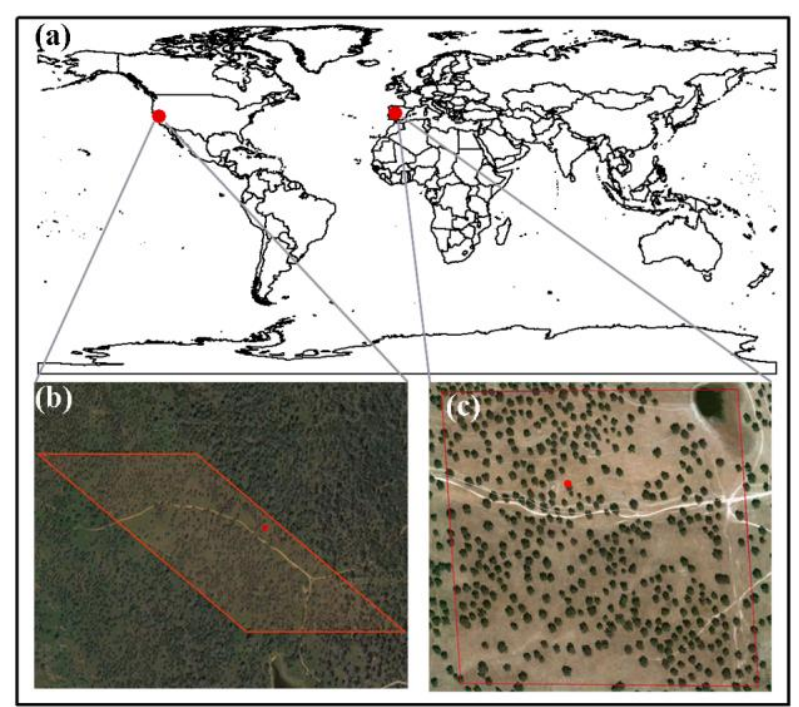




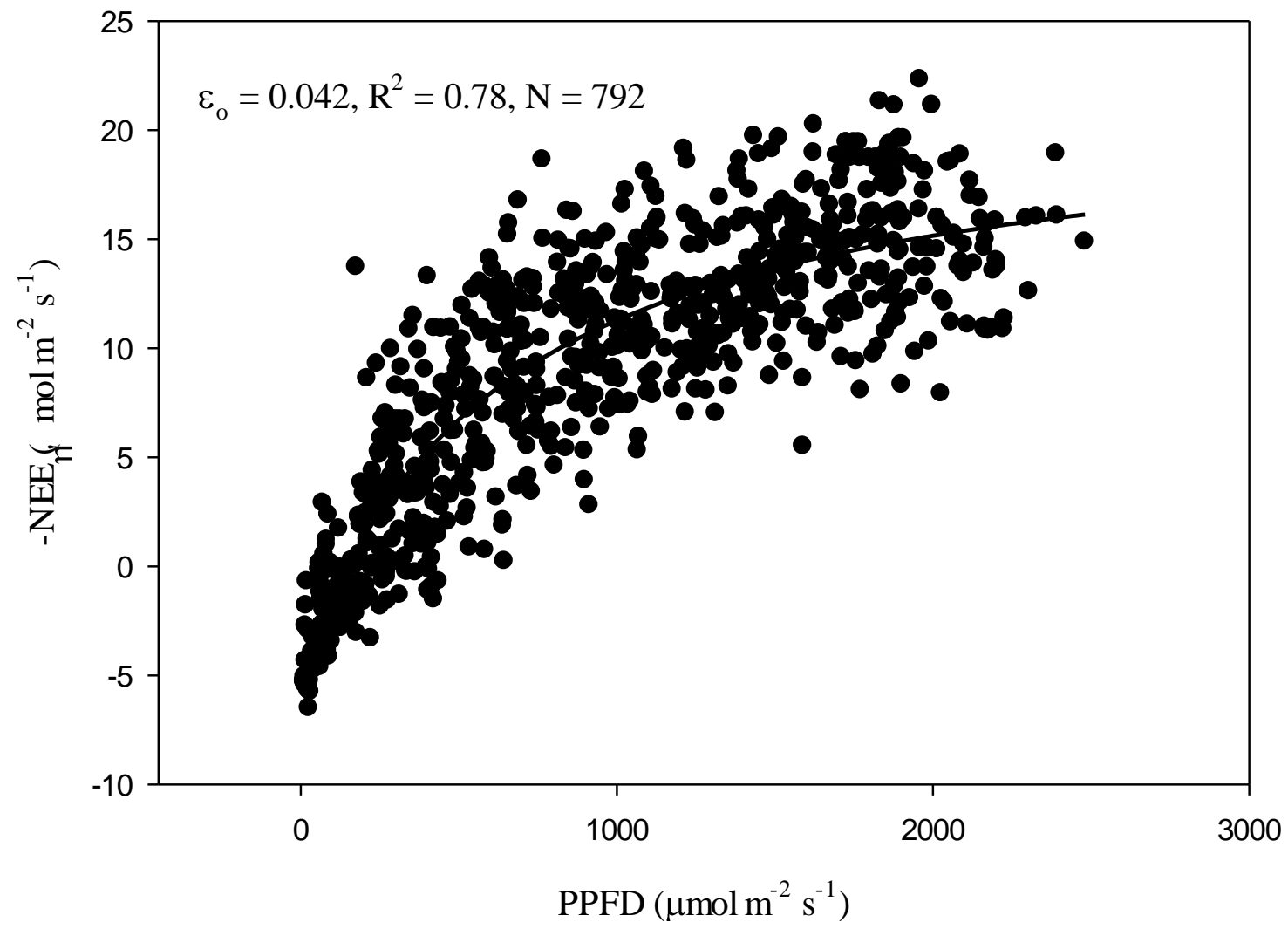

Fig2 


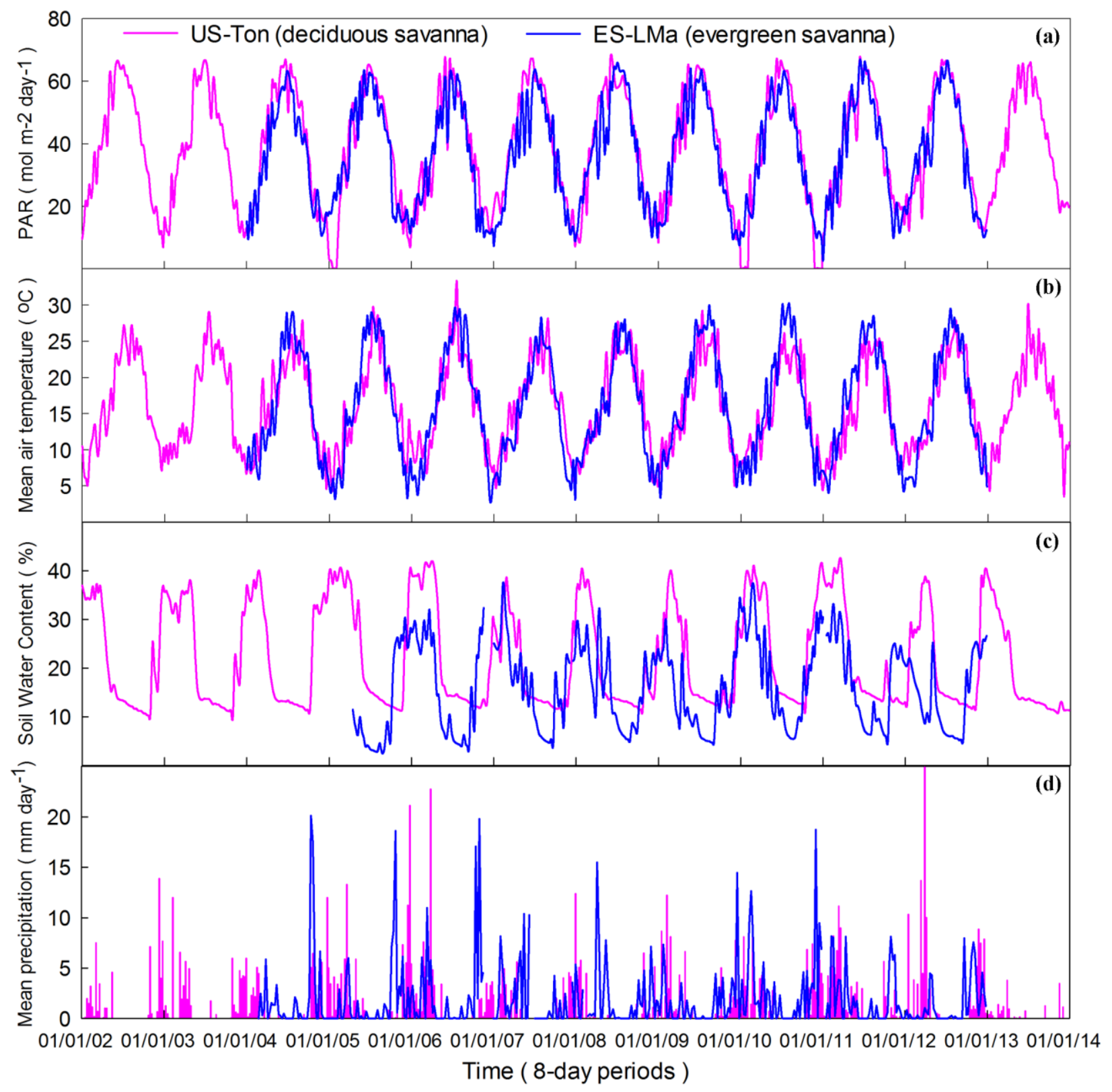




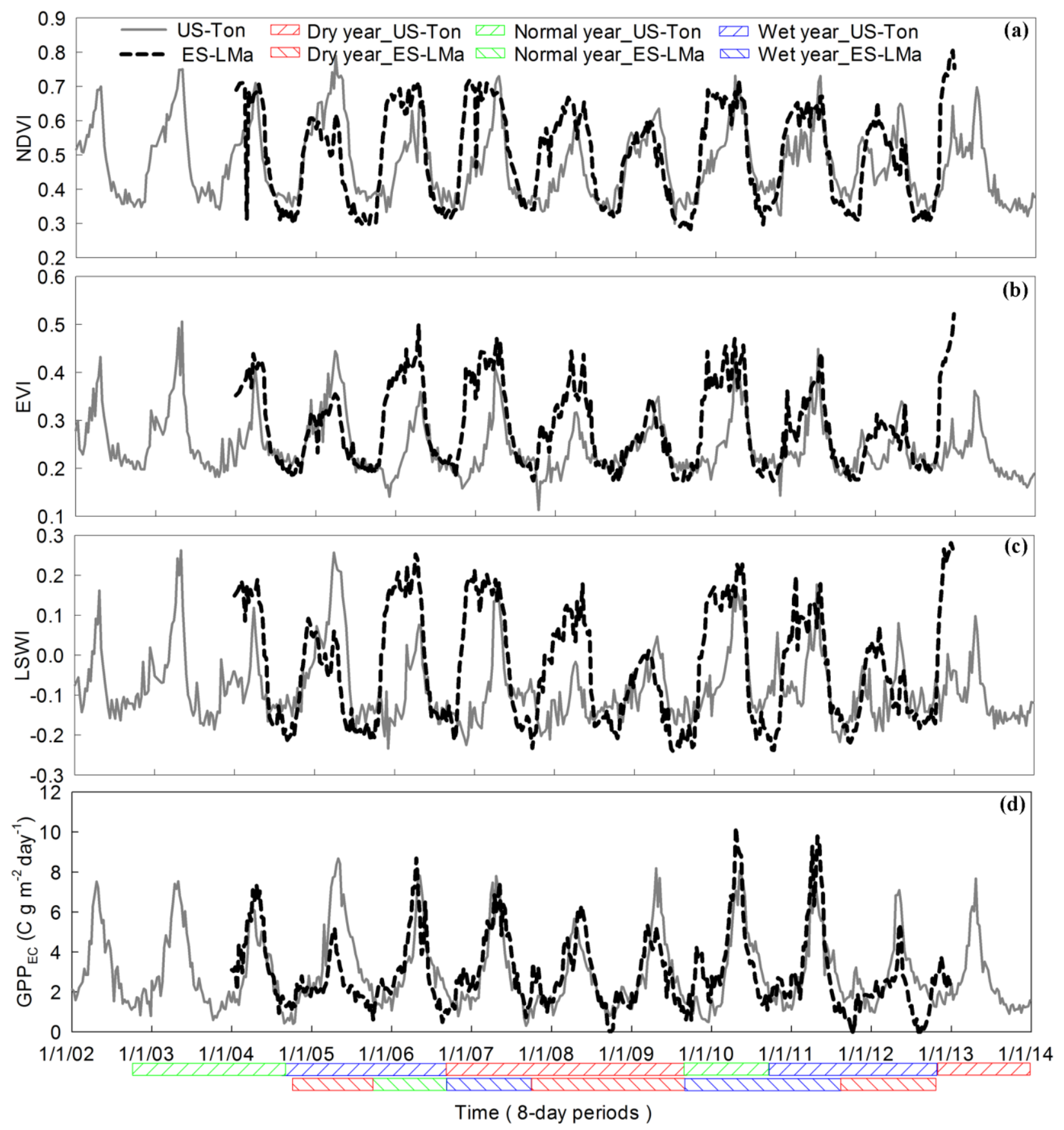




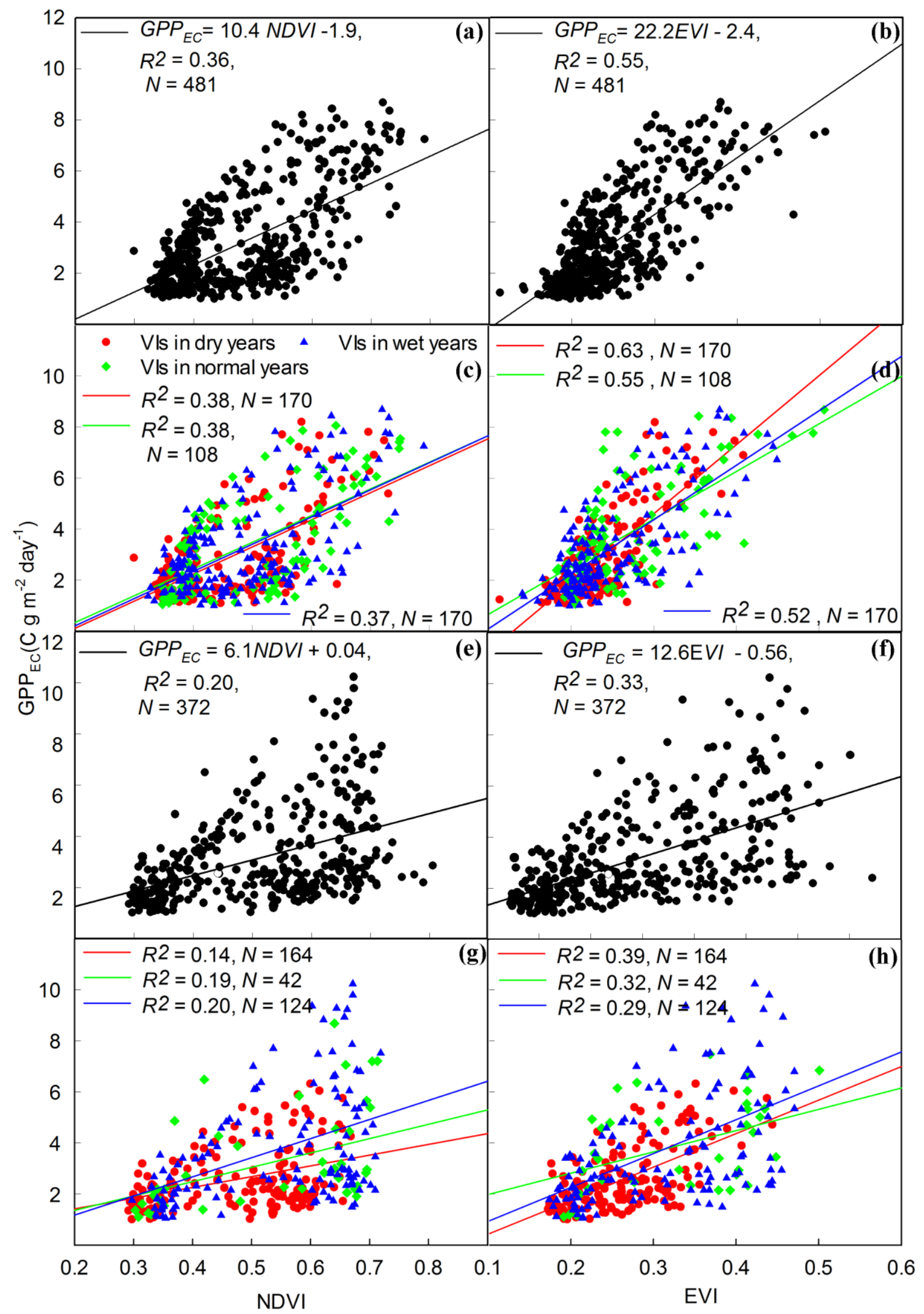




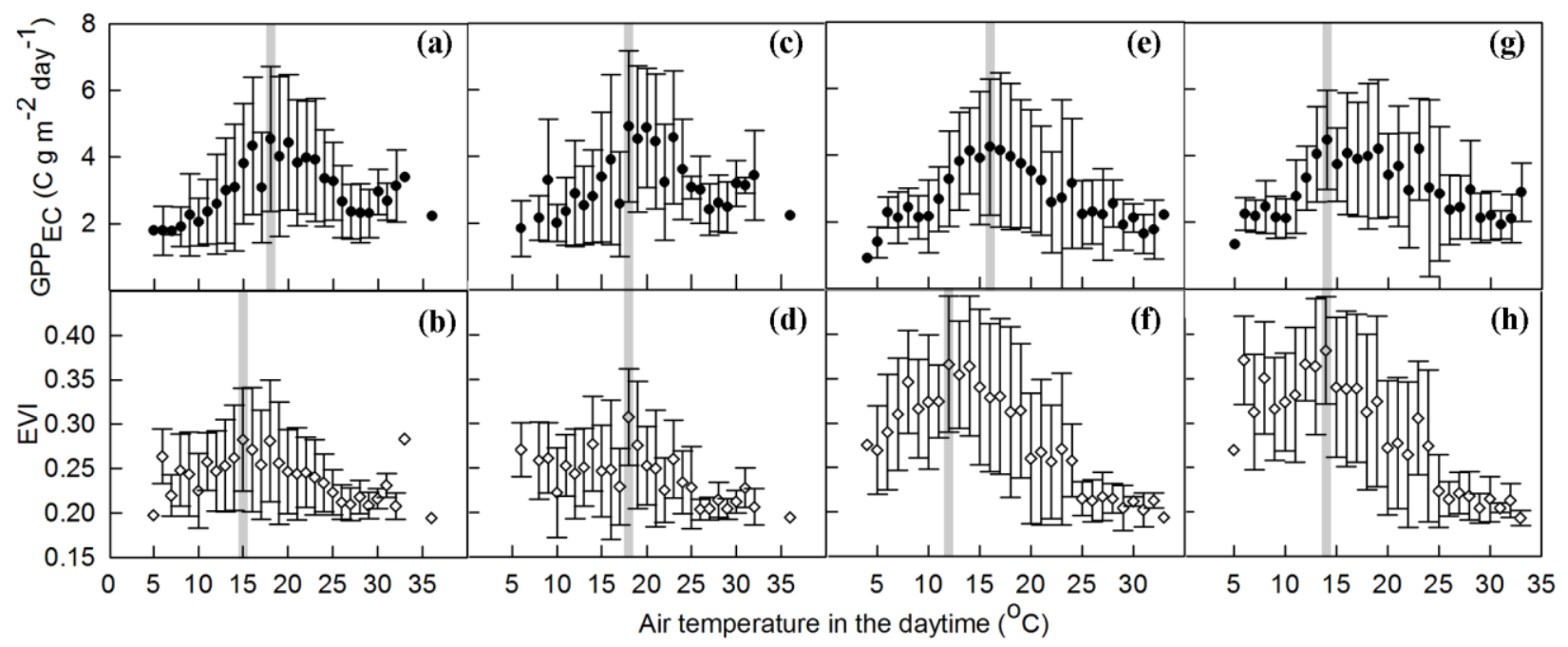




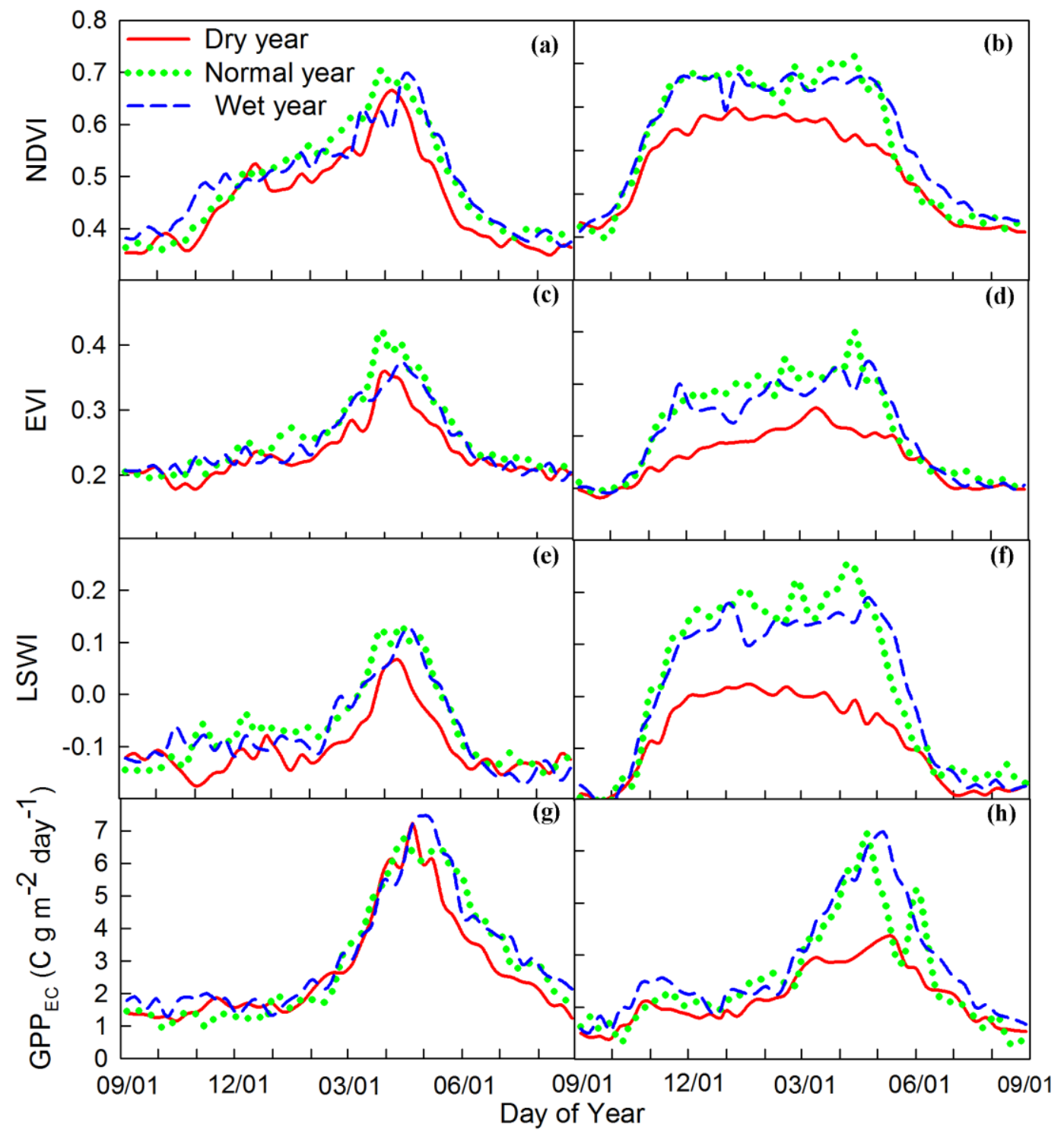




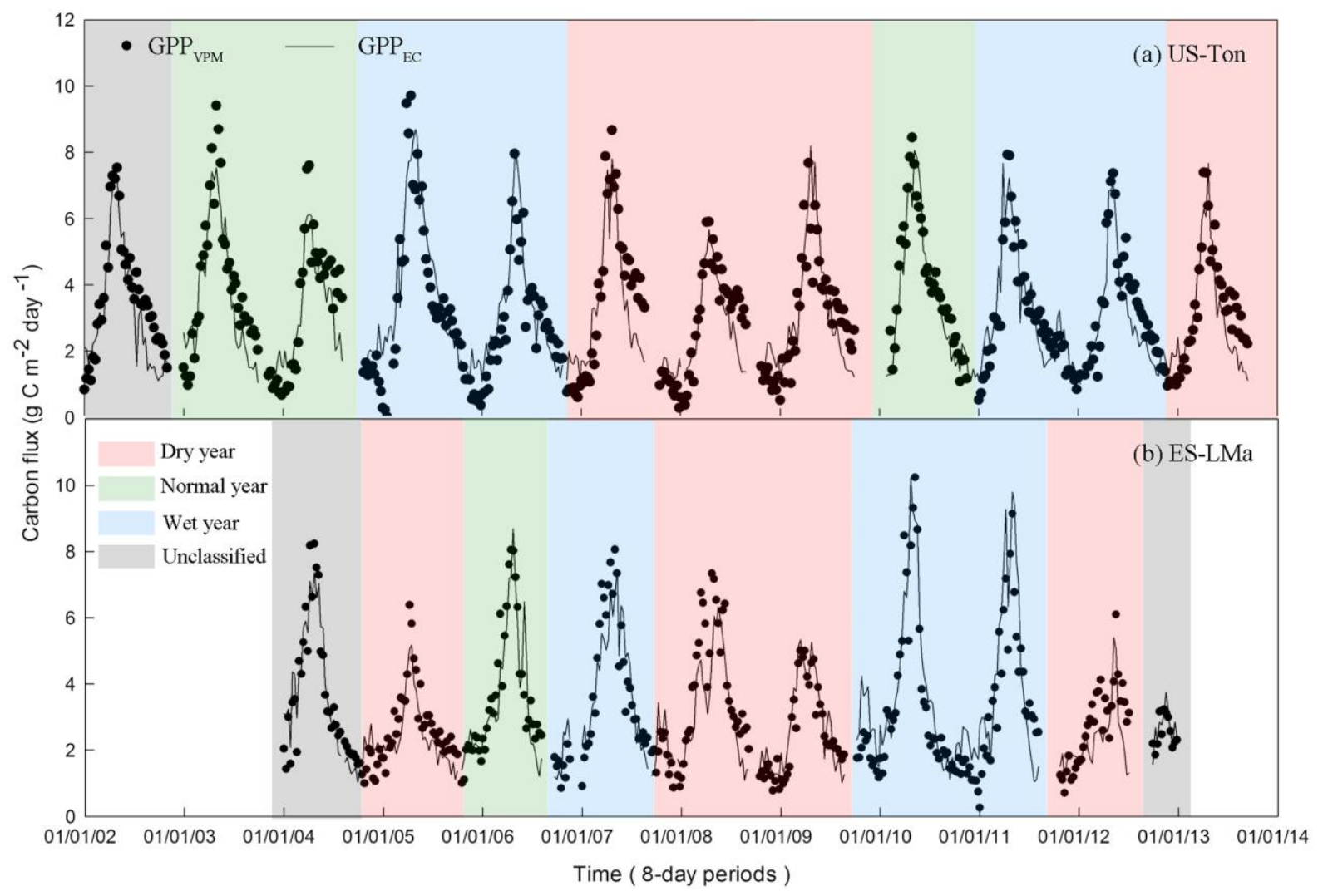




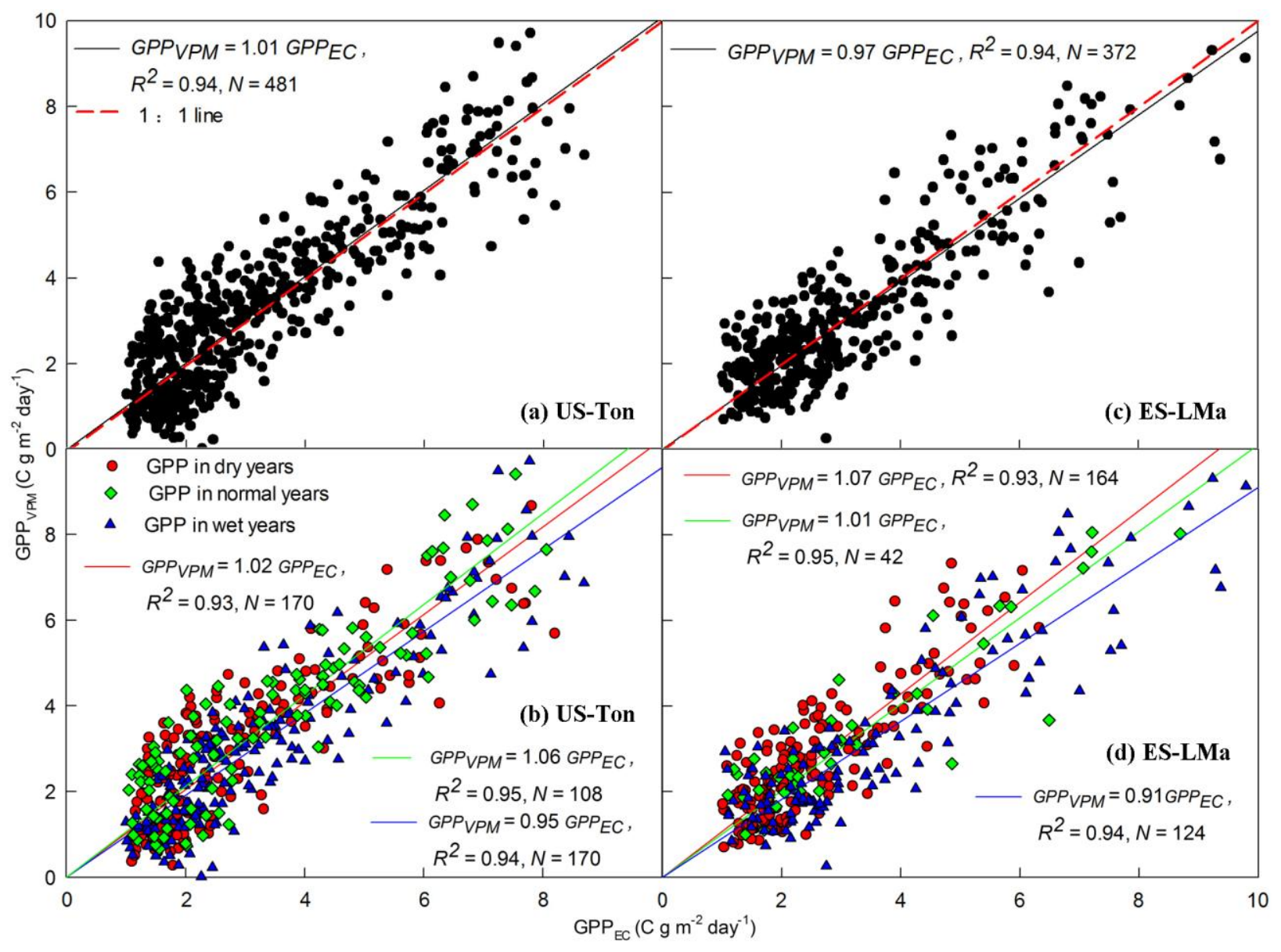




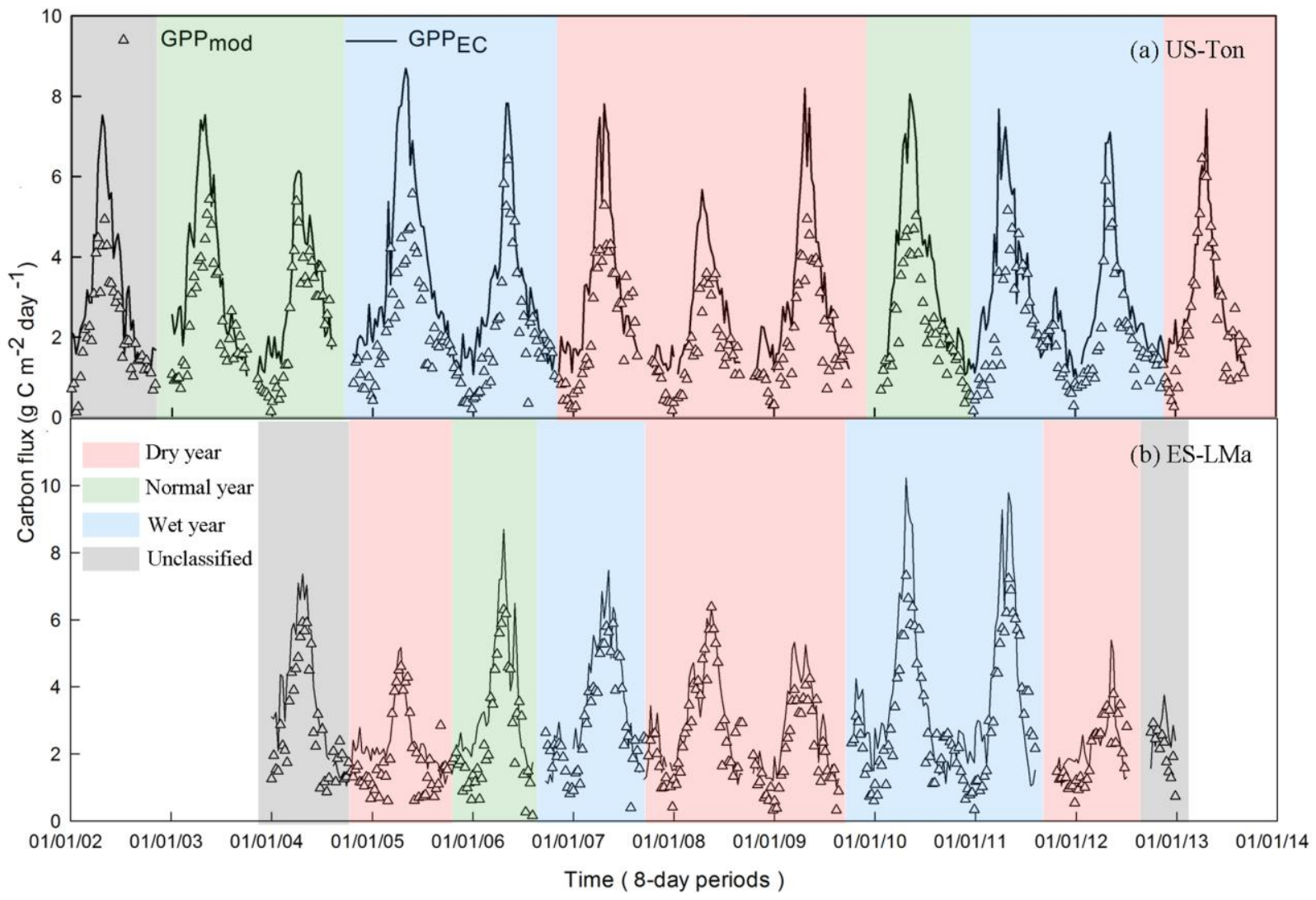



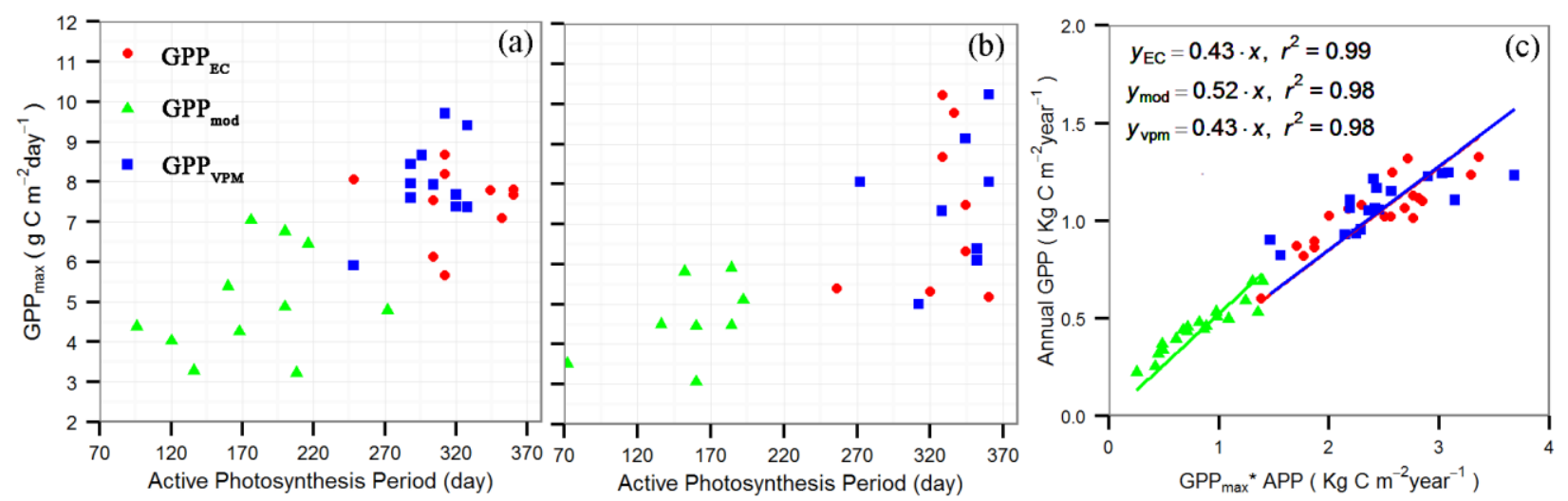


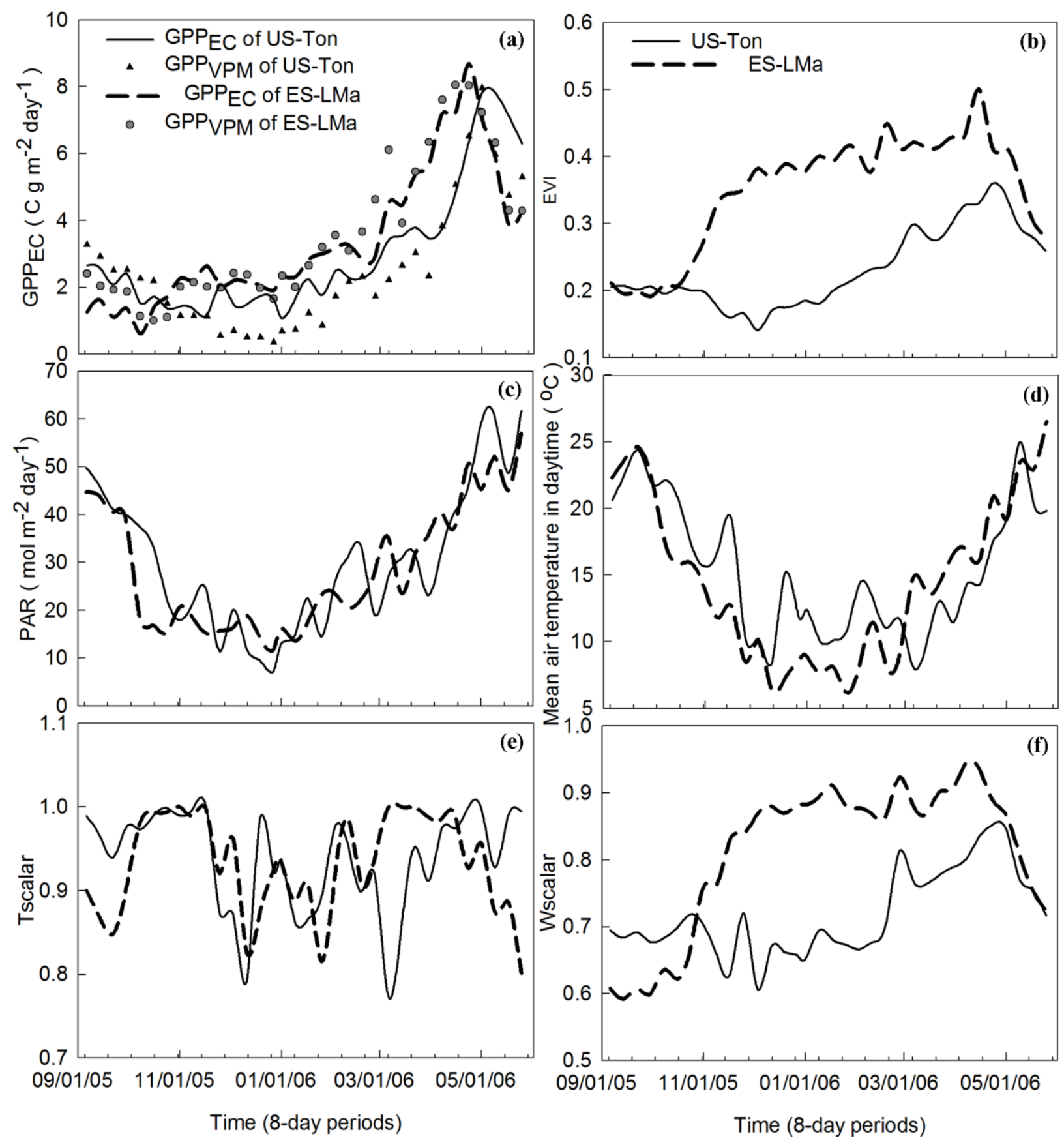




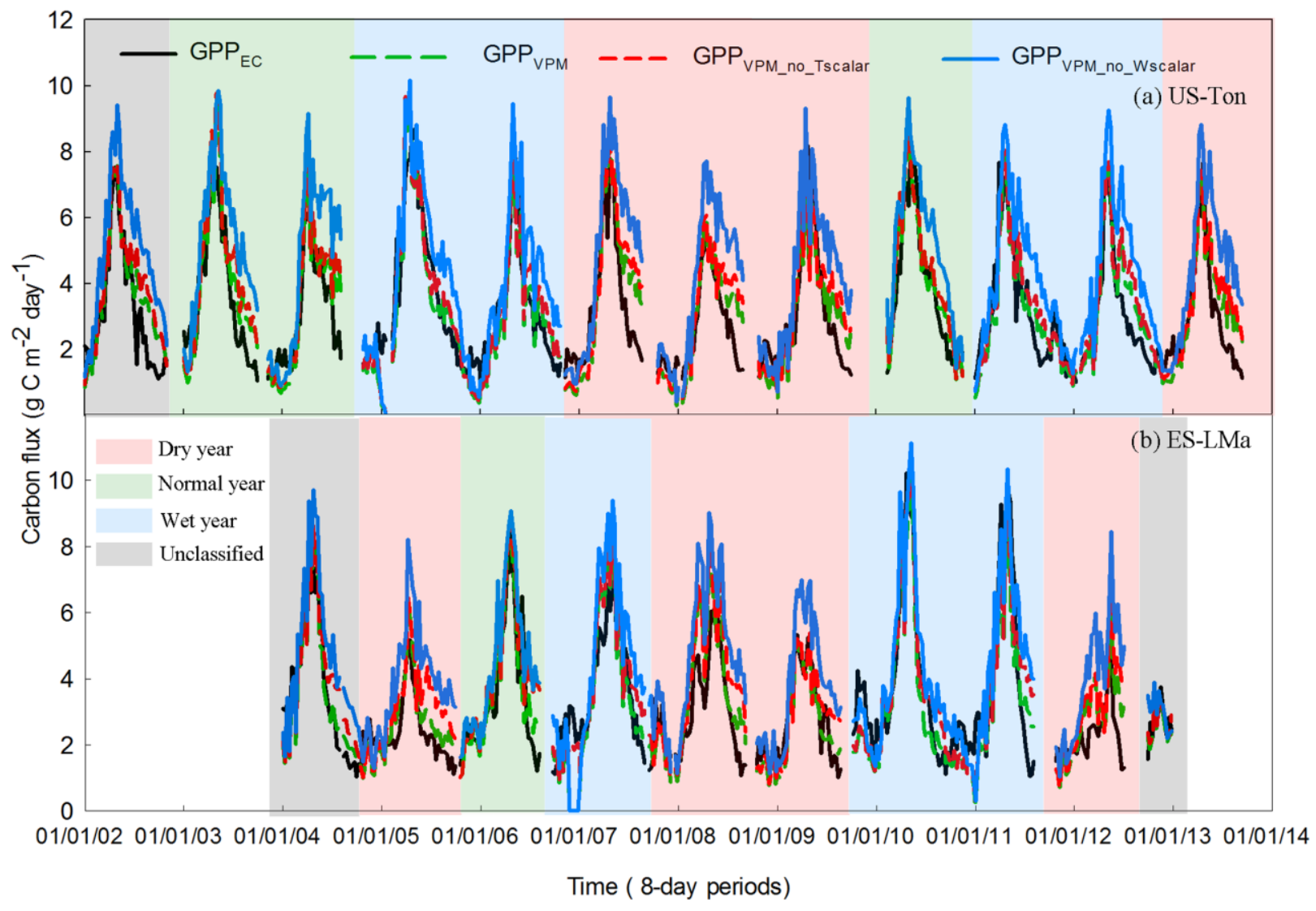

